\title{
Static load testing with temperature compensation for structural health monitoring of bridges
}

\author{
Viet Ha Nguyen ${ }^{a}$, Sebastian Schommer ${ }^{a}$, Stefan Maas ${ }^{a}$, Arno Zürbes ${ }^{b}$ \\ a University of Luxembourg, Faculty of Science, Technology and Communication, \\ Research Unit Engineering Sciences, Rue Coudenhove- Kalergi 6; L - 1359 Luxembourg \\ ${ }^{\mathrm{b}}$ Fachhochschule Bingen, Fachbereich 2 - Technik, Informatik und Wirtschaft, Germany
}

\begin{abstract}
:
The paper presents a series of repeated static loading tests on a prestressed concrete beam, which was originally part of a real bridge and then subjected to stepwise artificial damage. The tests were done during a one-month period that four levels of damage were introduced by cutting tendons until visible cracking occurred. The deflection line was measured by means of several displacement sensors and the retrieved information is used in different ways for damage detection.

At first, the sensor spacing requirement is analyzed with respect to measurement accuracy as well as necessary resolution for the numerical derivations of the deflection line to obtain the rotational angle and the curvature of the beam. These derived quantities may be used as damage indicators in addition to the deflection.

Damage of concrete goes very often along with non-linear phenomena like cracking of concrete and plastic strain of reinforcement steel. These effects are discussed and their influence on the repeated loading tests as well the test procedure for condition monitoring is deployed. Progressive damage goes along with progressive sagging of the bridge due to gravity, which can also be used as damage indicator.

Finally, the effect of varying outdoor temperatures are discussed and assessed. Though these effects can be reduced by choosing cloudy days without high temperature changes and without high solar irradiation, the outdoor temperature is never constant. Hence, a compensation algorithm is proposed which reflects the measured data according to a reference temperature. This compensation visibly improved the regularity of data.
\end{abstract}

Keywords: bridge, localization, damage, displacement, rotational angle, curvature, temperature, compensation

\section{Introduction}

Damage detection of bridges based on dynamic characteristics, i.e. modal parameters like eigenfrequencies, mode-shapes or damping ratios has been studied a lot in the last decades. For example, damage can be uncovered by reduction of eigenfrequencies or change of mode-shapes. The modal features are also used for subsequent procedures like finite-element model updating as illustrated on the Z-24 Bridge (Switzerland) [1] and the Gaertnerplatz Bridge (Germany) [2]. These parameters 
allow assessing experimentally stiffness/flexibility, as for instance reported for real bridges in Luxembourg [3, 4]. Damage in the I-40 Bridge in New Mexico was localized by a sensitivity analysis [5]. Further to detection and localization, assessment of damage can be realized $[1,4,6,7]$ and even a prediction of remaining lifetime is targeted $[8,9]$.

On the other hand, static load tests have a long tradition in civil engineering, provide important information on deformation, displacement, rotation and strain $[10,18]$. They have been since ever an appropriate alternative and an amendment to visual and dynamic inspections as deflection or strain measurements are relative easy. Static load testing within the service load limits have been used to validate new bridges and to verify the actual capacity of existing bridges. For example, before the opening to traffic in 10-2013, a new bridge in Grevenmacher (Luxembourg) connected to Wellen (Germany) over the Mosel River was undergone static load testing by six full charged trucks to archive the deflection line. For old bridges, this kind of test is very useful to check their present condition. In Florida [11], two prestressed concrete bridges were subjected to full-scale static tests where load testing vehicles delivered the ultimate live load. The results showed consistently that structures have greater residual strength than indicated by analysis or design. After 23 years of service, the real structural behaviour of the cable-stayed "Antonio Dovali Jaime" Bridge in Mexico was assessed [12]; after the load test campaign, residual deformations were not observed. A concrete arch bridge in Turkey, dates back to mid-to-late 19 th century and has approximately $8600 \mathrm{~km}$ of track length was checked by both dynamic and static load testing [13]. The static load test was performed by two diesel locomotive of DE24000 type and the load rating procedure proved the considerably safety of the bridge. Marefat $[14,15]$ studied the remaining load carrying capacity of two plain 60-year-old concrete arch bridges in Iran. By overloading compared to the expected service load, these bridges proved their satisfactory performance. However, the high load testing may provoke additional cracks and is hence not always appropriate.

Moreover, it is known that ambient temperature can change the stiffness of asphalt and bearings (pads, soil) and hence the static test results. Therefore, a temperature compensation procedure is discussed, used and evaluated below.

We got recently the chance to perform static and dynamic testing of a real prestressed concrete bridge prior to its demolishment. Increasing artificial damage was introduced in four successive steps and its effect on the static load testing within the service load limits is subsequently analyzed here, while the dynamic testing methods will be published in a companion paper. The relation between damage, static deflection, rotational angle, curvature and sagging together with unavoidable outdoor temperature variations are investigated.

\section{Description of the structure}

The tested structure was a part of the bridge, which was built between 1953 and 1955 and which crossed Mosel River between Grevenmacher (Luxembourg) and Wellen (Germany). It was demolished in 2013 and replaced by a new steel bridge. Some material tests were performed to verify the static strength of concrete and tendons for the bridge after 60-year service life. 


\subsection{Material Properties of the concrete}

Twelve cylindrical specimens of the concrete were taken in total and seven underwent so far compression or tension testing. The results are given in Table 1.

Table 1: Material properties of tested concrete specimens

\begin{tabular}{|c|c|c|c|c|c|c|c|c|}
\hline $\begin{array}{c}\text { Specimen } \\
n^{\circ}\end{array}$ & $\begin{array}{l}\text { Length } \\
{[\mathrm{mm}]}\end{array}$ & $\begin{array}{c}\text { Diameter } \\
{[\mathrm{mm}]}\end{array}$ & $\begin{array}{c}\text { Mass } \\
{[\mathrm{kg}]}\end{array}$ & $\begin{array}{l}\text { Density } \\
{\left[\mathrm{kg} / \mathrm{m}^{3}\right]}\end{array}$ & $\begin{array}{c}\text { Young's } \\
\text { Modulus [MPa] }\end{array}$ & \begin{tabular}{|c|} 
Poisson's \\
ratio
\end{tabular} & $\begin{array}{c}\text { Compression } \\
\text { strength [MPa] }\end{array}$ & $\begin{array}{l}\text { Splitting tensile } \\
\text { strength [MPa] }\end{array}$ \\
\hline 1 & 200 & 104 & 4,14 & 2439 & 42670 & 0,12 & 91 & -- \\
\hline 2 & 203 & 104 & 4,18 & 2426 & -- & -- & -- & 5,9 \\
\hline 3 & 204 & 104 & 4,23 & 2445 & & & & \\
\hline 4 & 202 & 104 & 4,19 & 2438 & & & & \\
\hline 5 & 204 & 104 & 4,17 & 2408 & 37130 & 0,14 & 67 & -- \\
\hline 6 & 202 & 104 & 4,16 & 2431 & 39180 & -- & 69 & -- \\
\hline 7 & 203 & 104 & 4,29 & 2483 & -- & -- & -- & 4,0 \\
\hline 8 & 203 & 104 & 4,17 & 2423 & & & & \\
\hline 9 & 203 & 104 & 4,27 & 2474 & 43290 & 0,13 & 75 & -- \\
\hline 10 & 204 & 104 & 4,16 & 2399 & -- & -- & -- & 5,8 \\
\hline 11 & 198 & 104 & 4,10 & 2443 & & & & \\
\hline 12 & 202 & 104 & 4,10 & 2392 & & & & \\
\hline \multicolumn{2}{|l|}{ Mean value } & & & 2433 & 40568 & 0,13 & 76 & 5,2 \\
\hline Variance & & & & 733 & 8524692 & 0,00 & 113 & 1,1 \\
\hline \multicolumn{2}{|c|}{ Standard deviation } & & & 27 & 2920 & 0,01 & 11 & 1,0 \\
\hline
\end{tabular}

\subsection{Prestressed tendons}

The concrete beam was prestressed by 19 steel tendons along the longitudinal direction of the beam, as shown in Figure 1 for a half of the symmetric beam.

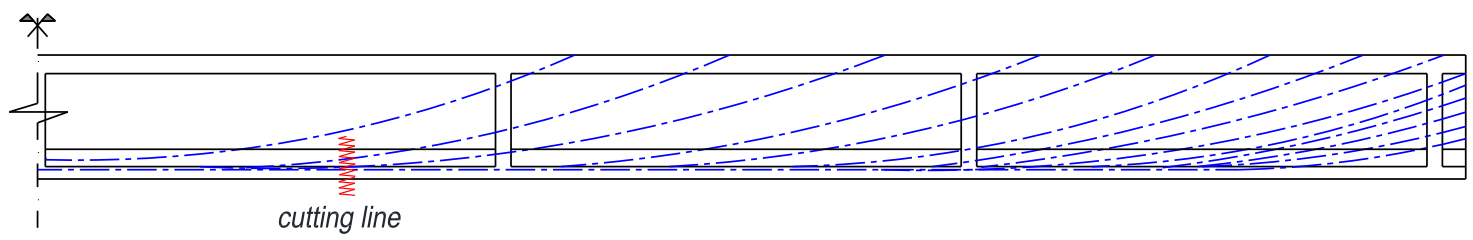

Figure 1 : Positioning of tendons along the beam's length, shown for a half of the beam

As shown in Figure 2, each tendon was composed of 12 steel wires of $7 \mathrm{~mm}$ diameter; they surrounded a spring that runs along the axis of the tendon. The whole tendon laid in a sheathing. During the construction of the bridge, the tendons were prestressed and subsequently grouted with mortar. This grouting was done to avoid corrosion and to fully connect the tendons to the concrete.

In Figure 2, the cross sections of some tendons show that they were not all fully filled with mortar. If the filling is not completely performed, corrosion is facilitated. In our test series of cutting tendons, a tendon without mortar showed higher decrease of strain than a completely surrounded tendon.

Corrosion and rupture of tendons lead to a local loss of prestress, which is normally first not visible from outside though it can be safety relevant. Depending on the level of prestress and the number of failed tendons that cracking of concrete occurs. As the tendons were grouted with mortar and the ends 
are in general not accessible, they cannot be tested just by pulling. Hence indirect testing methods are very interesting, e.g. those who are tracking the bending stiffness.
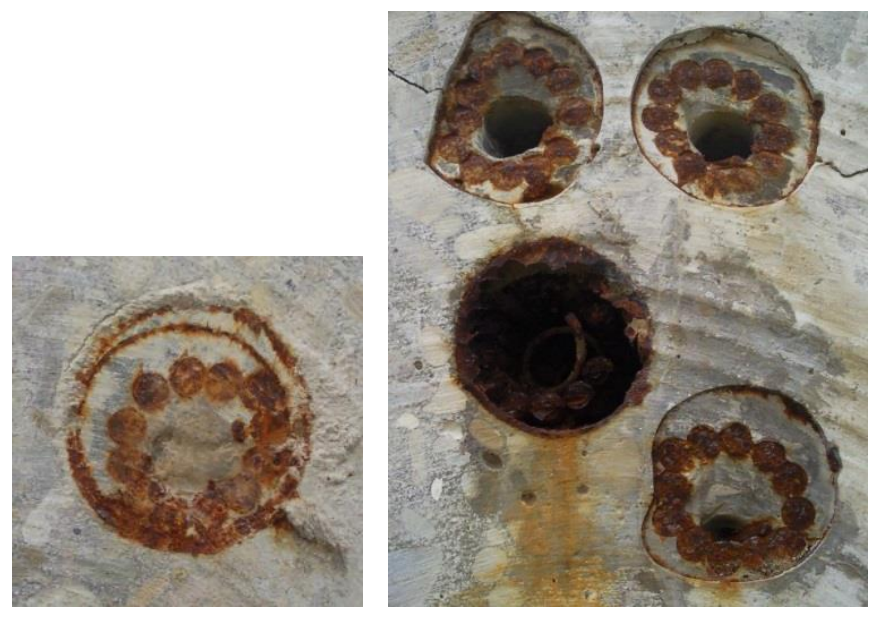

Figure 2 : Anchor heads of post-tensioned concrete beams

The remaining prestress in the steel tendons was measured in a destructive way, using strain gauges, which were glued on one of the 12 fibres of a tendon. Then this fibre was cut approximately $50 \%$ with an angle grinder leading to a forced rupture of the remaining section. Then the decrease of strain was registered with the strain gauge and in addition, the length of the visible gap between the two fragmented ends was measured with a sliding calliper.

In average a strain of $\varepsilon=3,28 \%$ and a gap of $\Delta l=2,25 \mathrm{~mm}$ were detected. Taking into account a Young's modulus of $E=2 \cdot 10^{5} \mathrm{MPa}$, the previously existing prestress can be calculated $\sigma_{p s}=E$. $\varepsilon$ $=2 \cdot 10^{5} \mathrm{MPa} .3,28 \cdot 10^{-3}=656 \mathrm{MPa}$.

The freed length $l_{0}$ can also be calculated: $\varepsilon=\frac{\Delta l}{l_{0}}$. So $l_{0}=\frac{\Delta l}{\varepsilon}=\frac{2,25 \mathrm{~mm}}{3,28 \cdot 10^{-3}}=0,69 \mathrm{~m}$.

The latter value means that approximately $0.7 \mathrm{~m}$ around the cutting position, the prestress will decrease by cutting a tendon. Farer away the tensile stress in the tendon will stay in consequence of back-anchorage due to friction. This effect was important for the numerical modelling and simulation where we set the prestress to 0 for a length of $0.7 \mathrm{~m}$, which are not discussed here.

\subsection{Situation of the testing beam}

The old bridge had 5 independent fields, each consisted of 5 parallel prestressed concrete beams carrying the driving lane. Two of these beams with a length of $46 \mathrm{~m}$ and a mass of about 120 tons each were shipped to the nearby port of Mertert for test purposes.

The idea was to simulate the situation during service-life of the bridge and then measure structural responses due to the planned tests. Therefore, one of the beams was jacked-up as simply supported beam as shown in Figures 3 and 4 . The fixed and sliding bearings were realized onto an existing railroad plus solid concrete foundation. First, two cast-in-place concrete blocks were made on the railroad and then the beam was lifted onto these blocks by a crane. One end of the beam was fixed to the concrete bloc in order to avoid movement in any direction. For the sliding bearing, two steel plates were placed 
between the beam and the concrete block and lubricated with grease. In fact, this was not a perfect sliding bearing because some friction still existed. But we clearly measured and document below longitudinal stick-slip movement of the beam, e.g. due to thermal expansion.

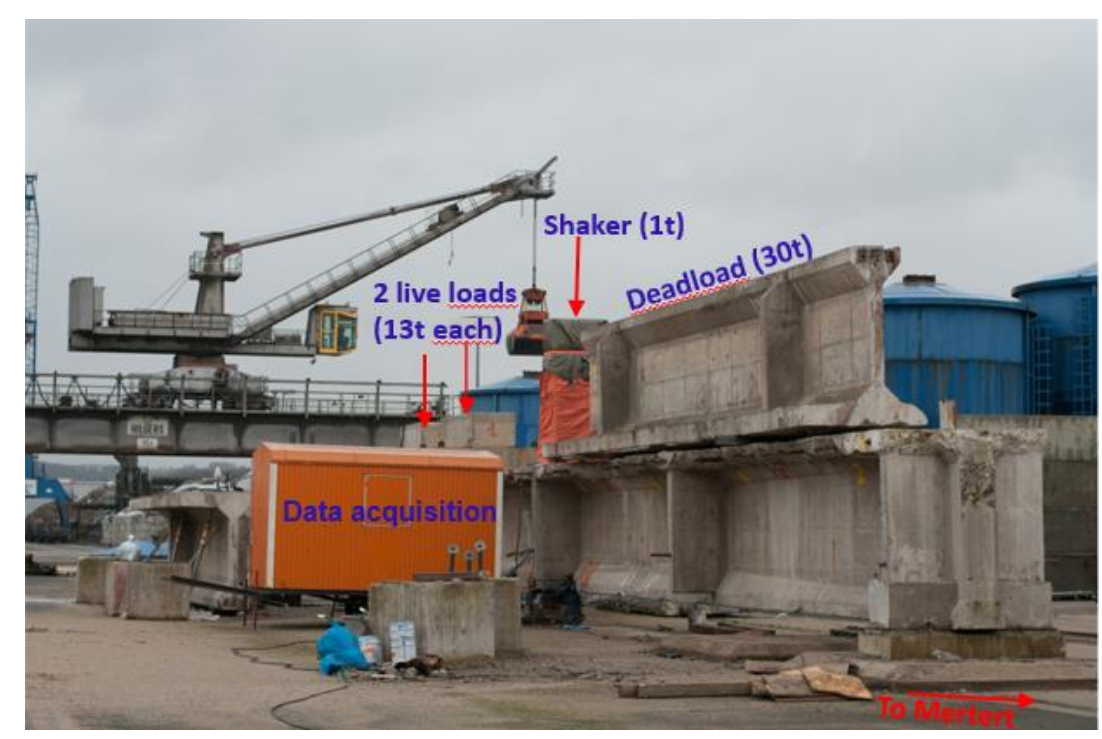

Figure 3 : Test set up

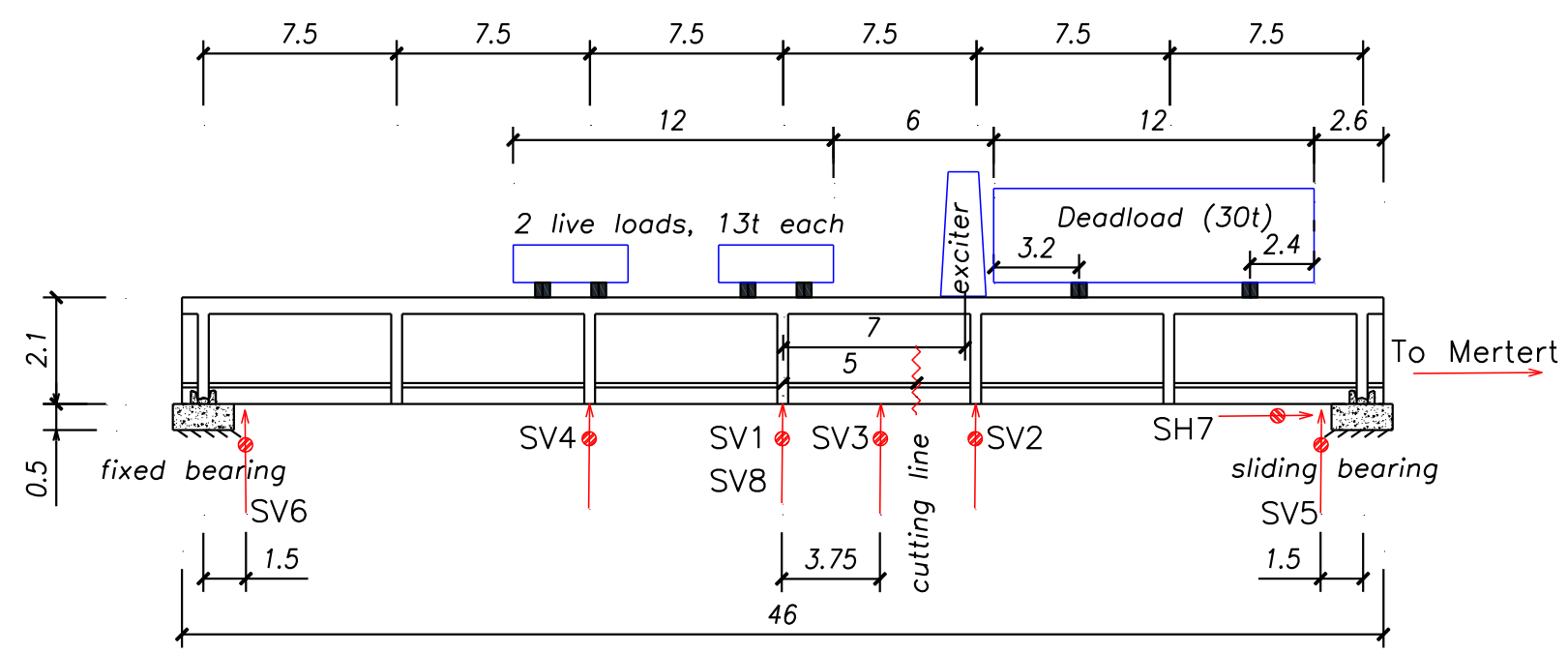

Figure 4 : Configuration of the beam and positions of transducers for static measurements

During the bridge's lifetime, the beams had not only to carry themselves but also the traffic lane with asphalt layer, sideway and other additions. In order to simulate this additional dead load, a part of the second beam with a mass of approximately $30 \mathrm{t}$ was cut and positioned on top of the structure. This mass stayed onto the beam during the whole test period and is hereafter referred to as dead load. Although it was not distributed equally over the whole beam length like an asphalt layer, its induced stresses were checked and considered as an equivalent approximation.

Furthermore for repeated static testing purposes with always the same mass loading, two concrete blocks with a mass of $13 t$ each were used and are subsequently denominated as live load. The bridge was subjected to similar charging due to high traffic loading during its life, i.e. the $26 t$ stayed within the permitted service loading. They were positioned on predefined and fixed wooden pads, and removed 
again after at least 24 hours. Displacements were recorded in several locations, as detailed in Figure 4, in the vertical (SV1-SV6, SV8) and the horizontal direction (SH7).

Transducer SH7 was placed near the sliding bearing to verify the horizontal movement of this bearing. Multiple vertical transducers were mounted in the axial direction in the middle of the crosssection to capture the deflection line. The two transducers SV1 and SV8 were placed off-centre at the outside of the flange at the same axial position to assess the beam's horizontal rotation, if present.

All static tests were performed between January 20 and February 19, i.e. within one month. During the whole time, the deflection of the beam and the ambient temperature condition were permanently registered. Figure 5 shows the set-up of eight temperature sensors: seven of them measured the temperature within a hole of $10 \mathrm{~cm}$ depth inside the concrete, while the eighth sensor recorded the ambient air temperature.

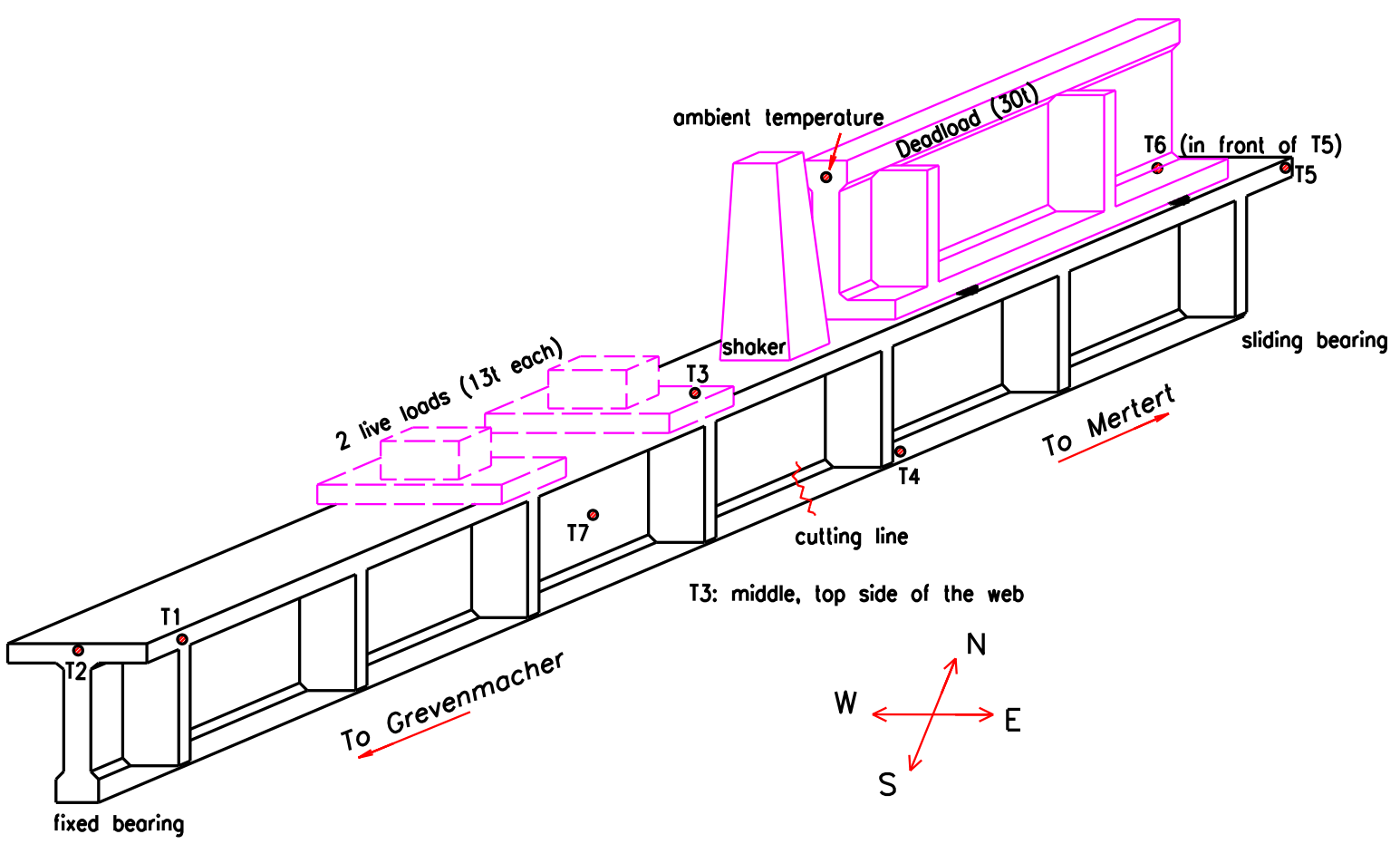

Figure 5 : Position of temperature sensors

\subsection{Discussion on the distance of transducers}

It is well known from the Euler-Bernoulli beam theory that the second derivative of the deflection $w(x)$, i.e. the so-called curvature $w^{\prime \prime}$ is proportional to the bending moment, while the first derivative $w^{\prime}$ is equal to rotational angle, which is a constant for a given cross-section. Therefore, the deflection line $w(x)$ measured by our vertical displacement sensors and its derivatives may be helpful for the identification and localization of damage. In practice, the measurements are done at discrete points along the tested structure and are usually sparse to limit the number of transducers. To assure precision and avoid measurement noise, we want at first to discuss the necessary distance between measuring points together with the measuring error, especially when it comes to numerical derivation. 
As an illustrative example, a simply supported beam is considered with length $l$, Young's modulus $E$, moment of Inertia $I$, under an evenly distributed constant load $q$. At a distance $x$ from the first bearing, the expressions for deflection $w$, slope $w^{\prime}$ and curvature $w^{\prime \prime}$ are analytically known and given below:

$w=\frac{q l^{4}}{24 E I}\left[\frac{x}{l}-2\left(\frac{x}{l}\right)^{3}+\left(\frac{x}{l}\right)^{4}\right] ; \quad w^{\prime}=\frac{q l^{3}}{24 E I}\left[1-6\left(\frac{x}{l}\right)^{2}+4\left(\frac{x}{l}\right)^{3}\right] ; \quad w^{\prime \prime}=\frac{q l^{2}}{2 E I}\left[\left(\frac{x}{l}\right)^{2}-\frac{x}{l}\right]$

By taking similar quantities as for our tested real concrete beam, as shown in Table 2:

Table 2: Principal features of the beam

\begin{tabular}{ccccc}
\hline$l$ & $E$ & $I$ & $\begin{array}{l}P=\text { total weight (selfweight, } \\
\text { deadload, live loads...) }\end{array}$ & $q=P / l$ \\
\hline $50 \mathrm{~m}$ & $4 . \mathrm{e}^{10} \mathrm{~N} / \mathrm{m}^{2}$ & $0,5 \mathrm{~m}^{4}$ & $2 . \mathrm{e}^{6} \mathrm{~N}$ & $40000 \mathrm{~N} / \mathrm{m}$ \\
\hline
\end{tabular}

Hence, the maximum curvature is in the middle of the beam $w_{\text {max }}^{\prime \prime}=-6,25 \cdot \mathrm{e}^{-4} \frac{1}{m}$.

Therefore $\left|w^{\prime \prime}\right|<6 . \mathrm{e}^{-4} \frac{1}{m}$ for the whole beam, a resolution $\Delta w^{\prime \prime}$ of $\mathrm{e}^{-5} \frac{1}{m}$ or at least $\mathrm{e}^{-4} \frac{1}{m}$ is necessary.

By approximating $w$ by $n$ equally distributed measuring points $\left(w_{1}, w_{2} \ldots w_{n}\right)$ along the beam with constant distance $a$, the $2^{\text {nd }}$ derivative at point $i$ can be approximated based on $2^{\text {nd }}$ order polynomial interpolation by $w_{i}^{\prime \prime}=\frac{1}{a^{2}}\left(w_{i}-2 w_{i+1}+w_{i+2}\right)$, with an error of $\Delta w_{i}^{\prime \prime}=\frac{1}{a^{2}}\left(\Delta w_{i}+2 \Delta w_{i+1}+\Delta w_{i+2}\right)$. If the measured precision of $\Delta w$ is $0.1 \mathrm{~mm}$ (a reasonable assumption with our used inductive displacement sensors), then the precision of the sum of 4 terms $\Delta w, \Delta w_{i}^{\prime \prime}$ corresponds to $\frac{1}{a^{2}} \cdot 0,4 \mathrm{~mm}$ or $\frac{1}{a^{2}} \cdot 4 \mathrm{e}^{-4} m$

For illustration purposes, for given distances $a$, different values of precision $\Delta w$ are assumed to calculate according to (4) $\Delta w_{i}^{\prime \prime}$, the achievable precision in Table 3:

Table 3: Values of $\Delta w_{i}^{\prime \prime}$ according to several precision $\Delta w$ and distance $a$

\begin{tabular}{|c|c|c|c|c|c|}
\hline $\begin{array}{l}\text { Precision } \\
\Delta w\end{array}$ & $\Delta w_{i}+2 \Delta w_{i+1}+\Delta w_{i+2}$ & $a=0,25 \mathrm{~m}$ & $\stackrel{w}{\prime \prime}^{a}=0,5 \mathrm{~m}$ & $a=1 \mathrm{~m}$ & $a=2 m$ \\
\hline $0,001 \mathrm{~mm}$ & $0,004 \mathrm{~mm}$ & $6,4 \mathrm{e}^{-5} \frac{1}{m}$ & $1,6 \mathrm{e}^{-5} \frac{1}{m}$ & $0,4 \mathrm{e}^{-5} \frac{1}{m}$ & $0,1 \mathrm{e}^{-5} \frac{1}{m}$ \\
\hline $0,01 \mathrm{~mm}$ & $0,04 \mathrm{~mm}$ & $64 \mathrm{e}^{-5} \frac{1}{m}$ & $16 \mathrm{e}^{-5} \frac{1}{m}$ & $4 \mathrm{e}^{-5} \frac{1}{m}$ & $1 \mathrm{e}^{-5} \frac{1}{m}$ \\
\hline $0,1 \mathrm{~mm}$ & $0,4 \mathrm{~mm}$ & $640 \mathrm{e}^{-5} \frac{1}{m}$ & $160 \mathrm{e}^{-5} \frac{1}{m}$ & $40 \mathrm{e}^{-5} \frac{1}{m}$ & $10 \mathrm{e}^{-5} \frac{1}{m}$ \\
\hline
\end{tabular}

When for instance a resolution $\Delta w^{\prime \prime}$ of $\mathrm{e}^{-5} \frac{1}{m}$ is required, it leads to: $\frac{1}{a^{2}} \cdot 4 \mathrm{e}^{-4} \frac{1}{m} \leq \mathrm{e}^{-5} \frac{1}{m}$; which results in $a \geq 6,3 m$. Or, a resolution $\Delta w^{\prime \prime}$ of $\mathrm{e}^{-4} \frac{1}{m}$ yields to $a \geq 2 m$.

According to the above table and assuming a precision of $0.1 \mathrm{~mm}$ for the measured displacement, a distance $a=2 m$ leads to an acceptable value of $\Delta w^{\prime \prime}$. This condition is satisfied in our present test set-up, as the smallest distance between transducers is 3,75 $m$ (Figure 4). So smaller sensors spacing " $a$ " offers finer deflection line but leads to a reduced resolution for slope and curvature, as the measuring precision for displacement is normally given and limited by the used sensor type. 


\subsection{Damage scenarios}

Before the beginning of the measurements, some finite element (FE) models of the beam have been created within the platforms ANSYS Classic and ANSYS ${ }^{\circledR}$ WorkbenchTM. Since concrete has a very low ultimate tensile strength (about ten times lower than the ultimate compression strength), a criterion for the appearance of first vertical cracks a tensile strength of $5.2 \pm 1 \mathrm{MPa}$ was supposed. According to the FE models, the first vertical crack will appear after cutting 6 of 19 tendons with loading the beam by the two additional masses.

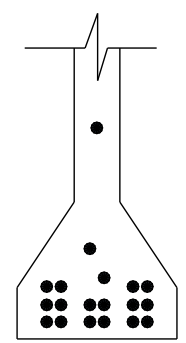

$\# 0$

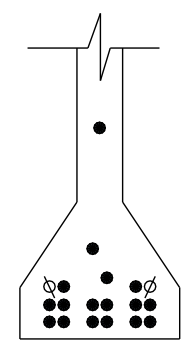

$\# 1$

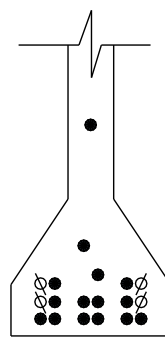

\#2

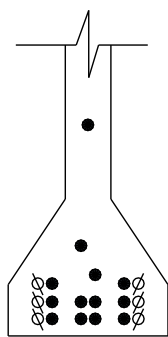

\#3

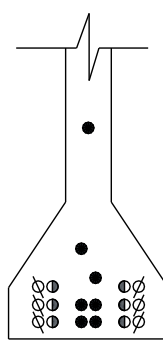

\#4

Figure 6 : Cutting of tendons in all the damage scenarios

Different damage scenarios were artificially provoked by cutting the tendons at the cutting line indicated in Figure 4 and Figure 5. The position of the tendons at the cutting line is shown in Figure 6 within the lower part of the beam's cross-section. A whitening of a tendon represents its cutting. The initial state \#0 and other four damages \#1 to \#4 are reported in Table 4. Within each damage state, the tendons were cut symmetrically in the cross-section. For damages \#1 to \#3, all wires of the tendons were fully cut because they were all well accessible after removing the concrete cover. However, for the last damage scenario \#4, tendons were only partially cut because the inner wires could not be reached without removing filled surrounding concrete. Consequently, only half of the fibres were cut for each tendon, as illustrated in Figure 6 for damage \#4. The situation of cutting and cracking are represented in Figure 7 and Table 4.

Table 4: Damage scenarios

\begin{tabular}{|c|c|c|}
\hline Scenario & Cutting of & Observation of cracking \\
\hline$\# 0$ & 0 tendon & \\
\hline$\# 1$ & 2 tendons & $\begin{array}{l}\text { Horizontal cracks appeared near the cutting line due to } \\
\text { shear stresses caused by back-anchorage of the cut } \\
\text { wires due to friction }\end{array}$ \\
\hline \#2 & 4 tendons & Enlargement of horizontal cracks \\
\hline \#3 & 6 tendons & $\begin{array}{l}\text { First vertical cracks, above the cutting line; extension } \\
\text { of horizontal cracks }\end{array}$ \\
\hline \#4 & $\begin{array}{l}6 \text { tendons }+ \text { half of } 6 \text { others } \\
\text { tendons }\end{array}$ & $\begin{array}{l}\text { More vertical cracks near the cutting line; extension of } \\
\text { existing cracks }\end{array}$ \\
\hline
\end{tabular}




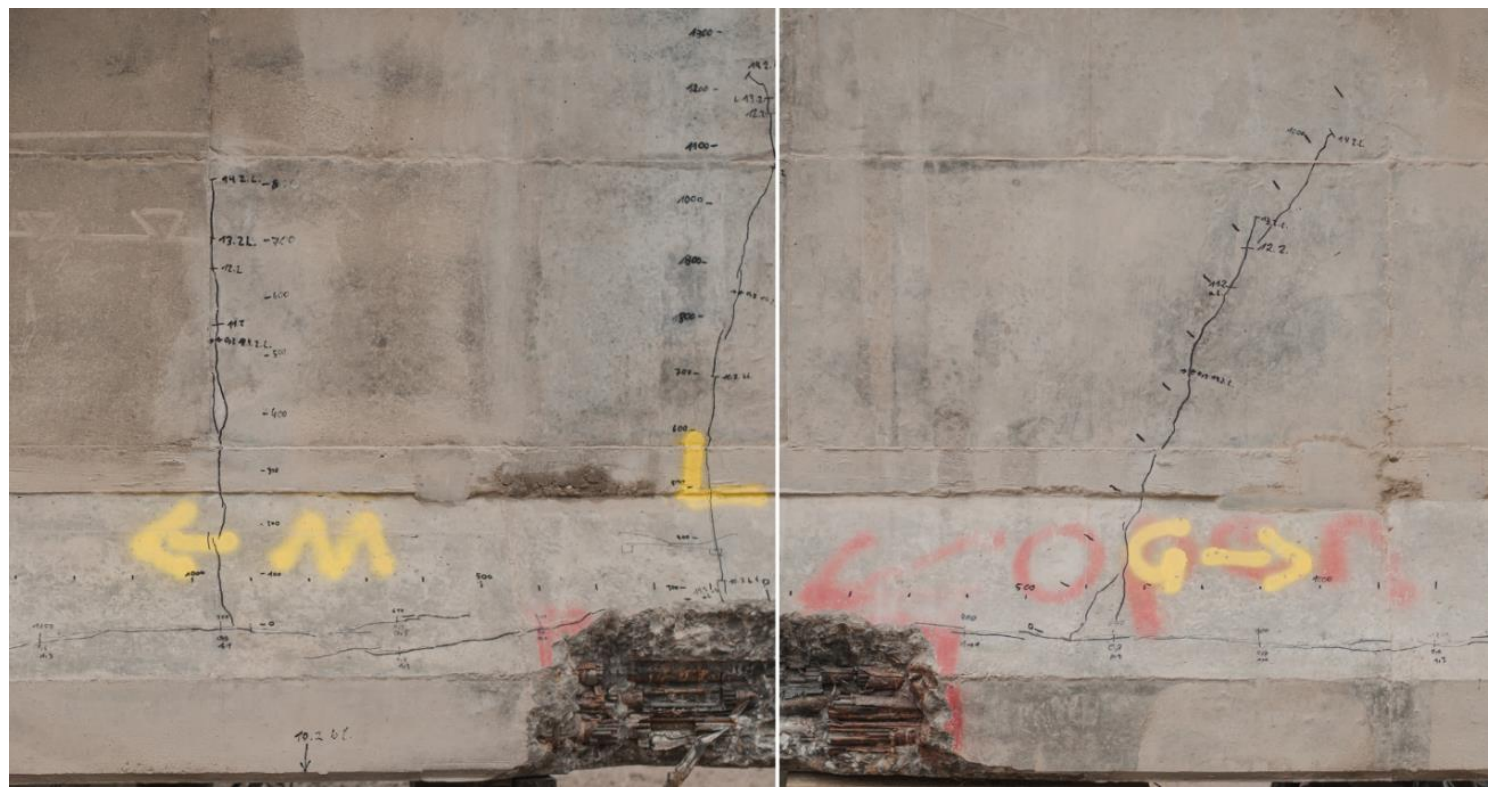

Figure 7: Cracks observed in damage scenario \#4

\section{Data processing}

\subsection{Overall measured displacements}

To check the measuring precision of the 8 displacement transducers and the stiffness of the bearings, an independent optical measuring system was used from a distance of several meters. The two live loads were positioned on the beam for 2 hours and then removed again. The results of the optical system were compared with the inductive sensors in Figure 8. This test proved that the displacements of the bearings are smaller than $0.29 \mathrm{~mm}$ and that our test set-up was fine.

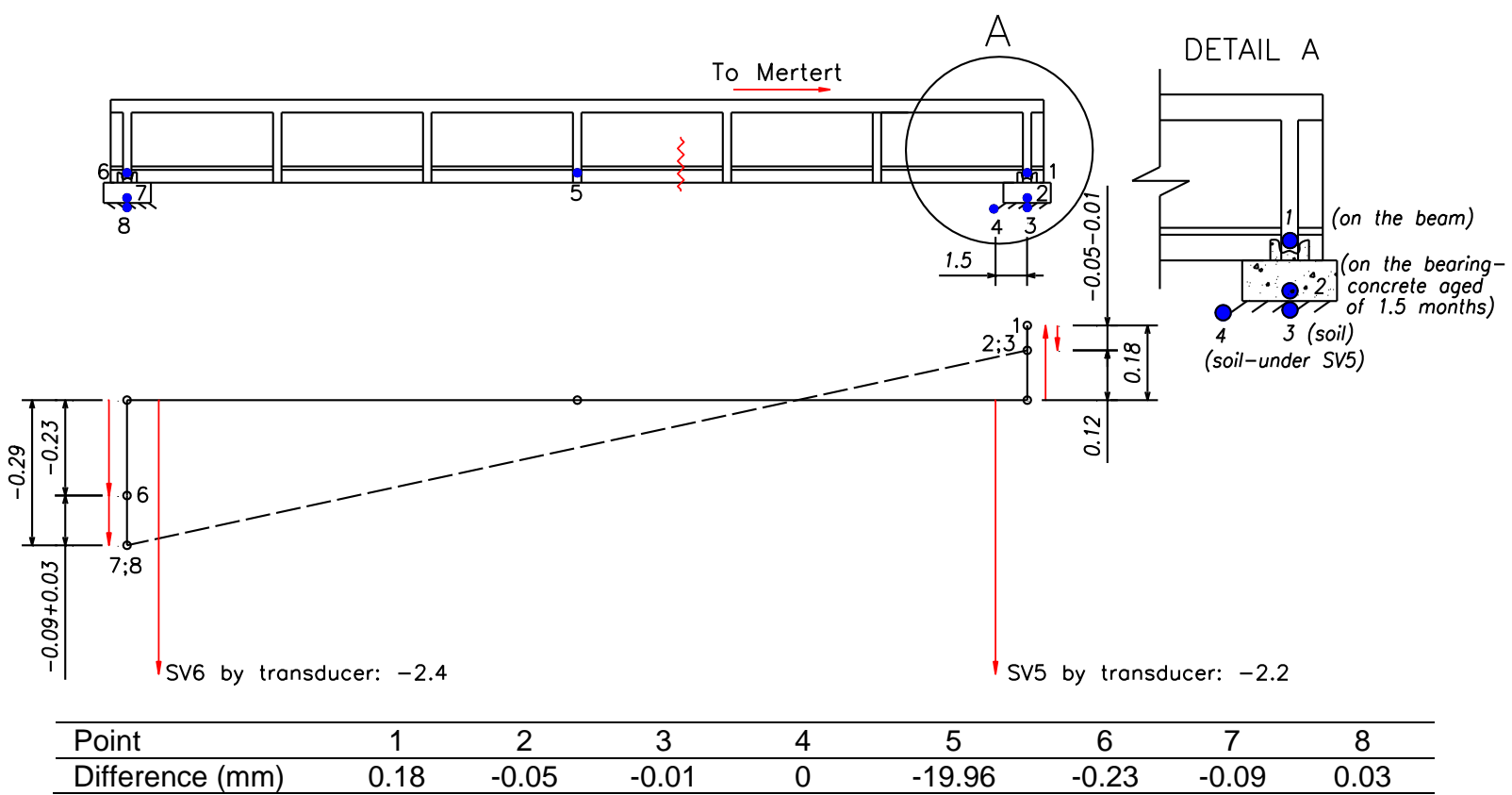

Figure 8: Optical measurements on 29 January (marked in Figure 9)

Figure 9 shows nine measured displacement-time signals from January 20 to February 19, i.e. a period of one month. The two principal different situations of loaded (L) and unloaded (UL) can clearly 
be separated: a loading was performed by putting the two weights of 13 tons each on the top of the beam as indicated from Figure 3 to Figure 5 . In total, there are nine loadings, but the first two ones are considered as "test-only" and hence not evaluated later on. Hence, only seven loading are examined, always referring to the damage scenarios defined in Table 4 and indicated in Figure 9 in green segments at the top. For instance, "\#0-L1" means loading 1 in scenario \#0, while "\#0-L2" designates loading 2 in the same damage state.

The static displacement gives important information about damage and its localization. Sensors of special importance are SV3 and SV2, which are left and right to the cutting line (see Figure 4). Let us recall that Figure 9 contains the complete static loading test history for every damage state. Before scenario \#3 was applied, the two sensors in the middle SV1 and SV8 of the beam show the highest readings; but from \#3 onwards, i.e. after $6^{\text {th }}$ February, the SV3 (red) signal passes by SV1 and SV8. The sudden rise of displacements SV2 and SV3 corresponds to the formation of vertical cracks and their opening between these transducers. Thus, the maximum deflection was no longer in the middle, but at the location of the crack, which is indeed an efficient way to localize damage.

Another important phenomenon can be observed in damage scenario \#4, when there are two subsequent loadings in one damage state. The graph shows a clear diminution of displacement from the first \#4-L1 to the second \#4-L2 loading. During the first loading (L1), a plastic, i.e. non-reversible deformation took place, which is a well-known phenomenon when yield stress of metal or when the crack load of reinforced concrete is exceeded, ref. e.g. [16]. Figure 10 shows the principal stress-strain behaviour in this case: during the first loading (L1), the deformation was at the beginning elastic (segment $\mathrm{OA}$ ) and then evolved to plastic (segment $\mathrm{AB}$ ). With unloading (BC segment), the beam's behaviour followed a straight line parallel to $O A$ until zero stress level, leaving a residual strain $(O C)$ and so a residual deformation. A subsequent $2^{\text {nd }}, 3^{\text {rd }}$...etc. loading $(L 2, L 3, \ldots)$ up to the same maximum stress from $C$ follows the line $C B$. Hence, the total strain in $L 1 \varepsilon_{\text {total }}$ is significantly higher than the elastic strain in $\mathrm{L} 2 \varepsilon_{\text {elastic }}^{C B}$. Figure 10 reveals clearly the non-linear behaviour including plastic, non-reversible deformation. 


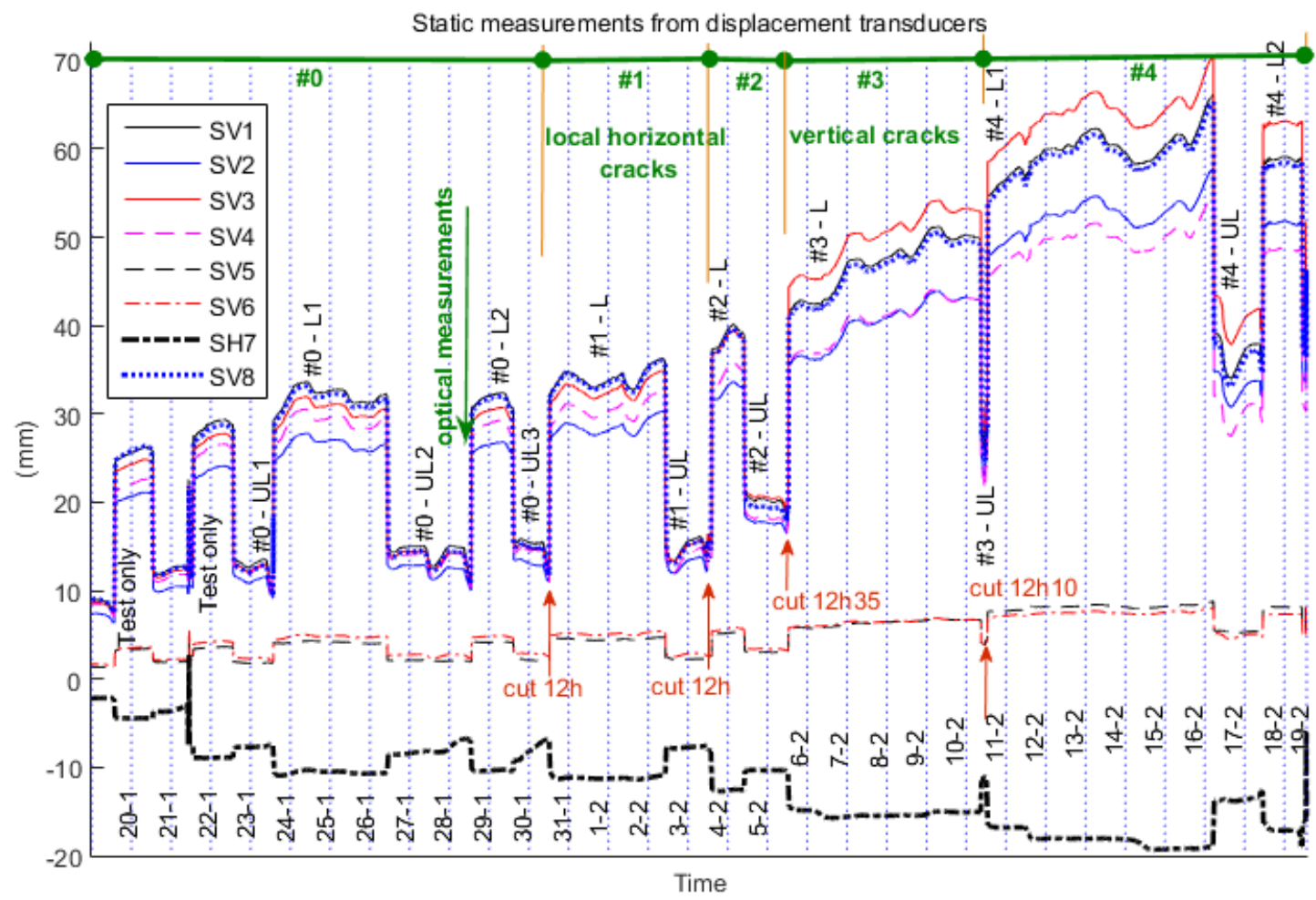

Figure 9 : Static measurements from transducers for 7 vertical and 1 horizontal displacements

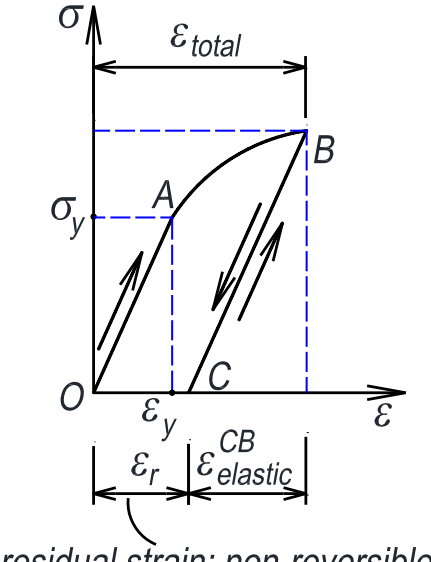

Figure 10: Stress-strain diagram for a loading-unloading procedure

Therefore, returning to the present work, Figure 11 highlights this effect for scenario \#4 where two subsequent loadings with the same force were performed without changing the artificial damage state. For sensor SV1 (in the middle), a decrease of 25.8-22.2=3.6mm can be seen in Figure 11a, while Figure $11 \mathrm{~b}$ reveals the overtaking of the sensor close to the crack (SV3) with respect to the sensor in the middle (SV1). 


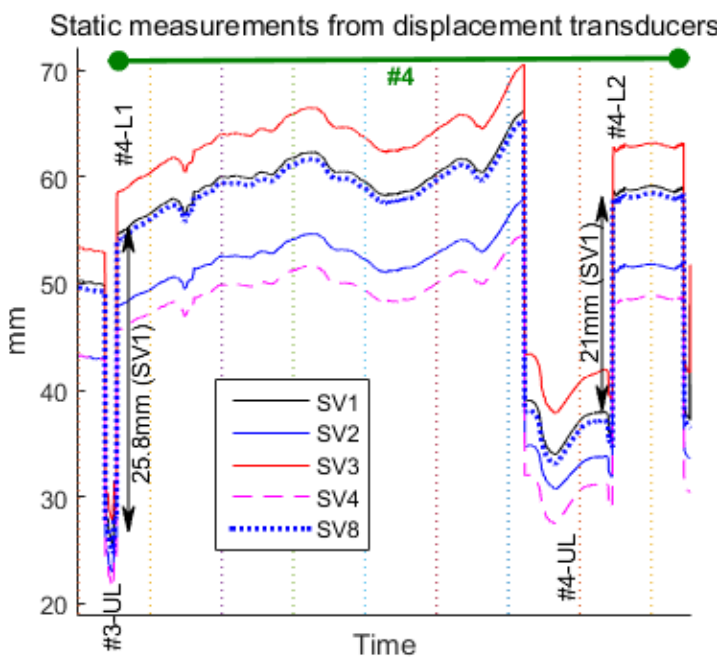

a) Zoom for two loadings within scenario \#4,

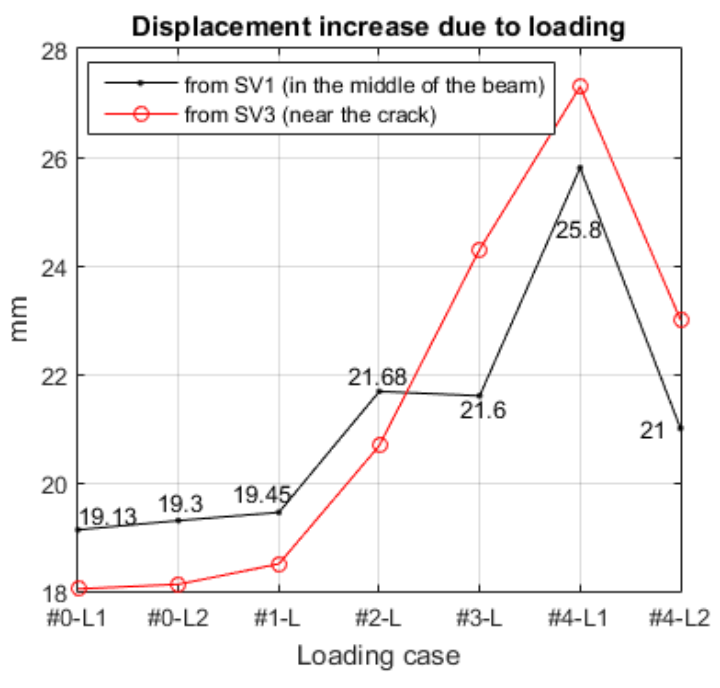

b) Report for 7 loadings

Figure 11 : 'Jump' of displacement signals due to mass loading

We address now the residual deformation due to creep and plastification in the beam, which is already clearly visible in Figure 9. Sensor SV3 (red) started in unloaded condition (UL) at an absolute position of $\approx 9 \mathrm{~mm}$ on January 20 and reached $\approx 43 \mathrm{~mm}$ on February 17 , i.e. highlighting a sagging of $34 \mathrm{~mm}$. As the first loadings are served as "test-only", by taking the starting of SV3 by midday on January 24 at an absolute position of about $10 \mathrm{~mm}$ before the loading, the sagging is accordingly about $33 \mathrm{~mm}$ after the seven considered loadings. Figure 12a gives a zoom of damage scenario \#4 where the highest sagging (at SV3) of $12.1 \mathrm{~mm}$ is indicated. Figure 12b shows the summary over all scenarios for sensors SV1 (middle) and SV3 (near the crack). The calculation of SV3 values in Figures 12b are also illustrated in Figure $12 \mathrm{c}$ by two thin curves presenting SV3 recorded before and after each loading. The residual displacement per load step is assessed by the gap between these two curves. The sagging of $33 \mathrm{~mm}$ can be easily read by comparing the first value of the "before loading" curve and the last value of the "after unloading" curve. Another curve is also built in the last graph, in bold magenta line, to present accumulated residual displacement as long as load steps. The final accumulated value attains $45 \mathrm{~mm}$, which is bigger than the sagging of $33 \mathrm{~mm}$. The reason is unavoidable difference between the data recorded after an unloading and before the loading of the next load step, e.g. \#0-L1 and \#0-L2, \#0-L2 and \#1-L. 


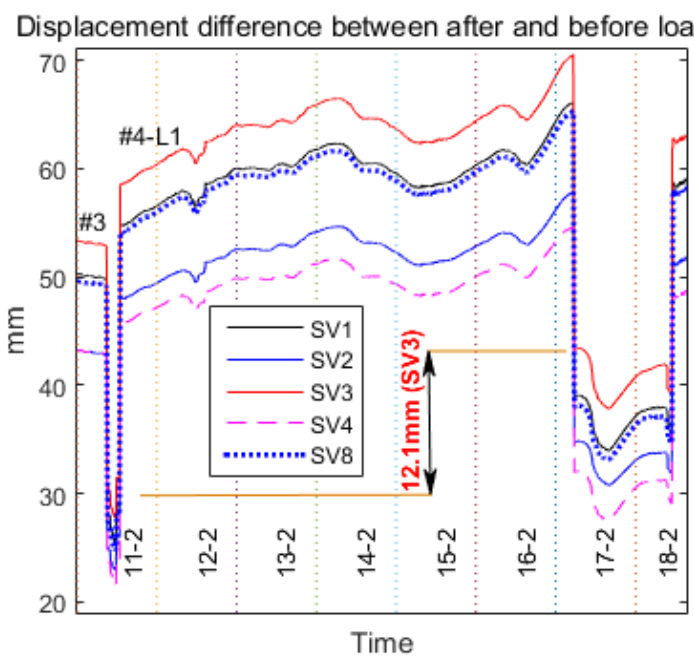

a) Zoom for the $1^{\text {st }}$ loading in scenario \#4 (\#4-L1), residual deformation in SV3 is $12.1 \mathrm{~mm}$

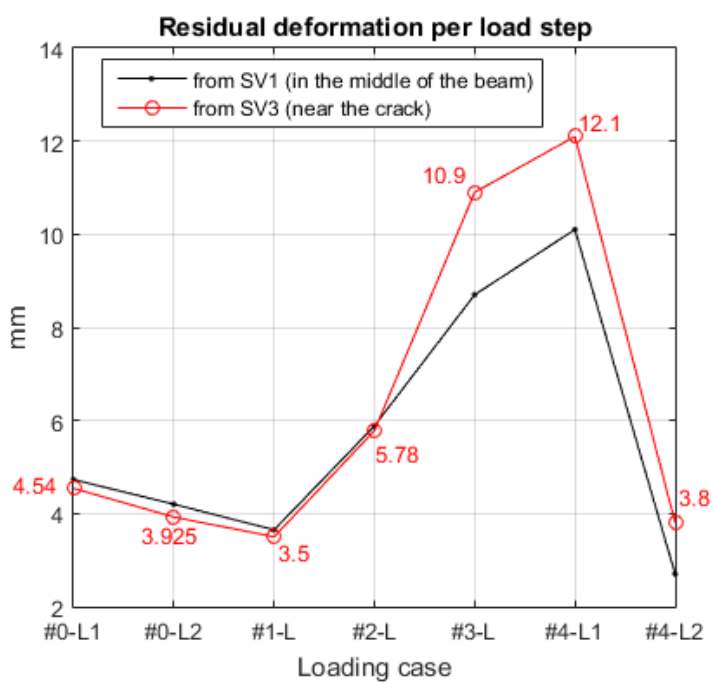

b) Report for 7 loadings

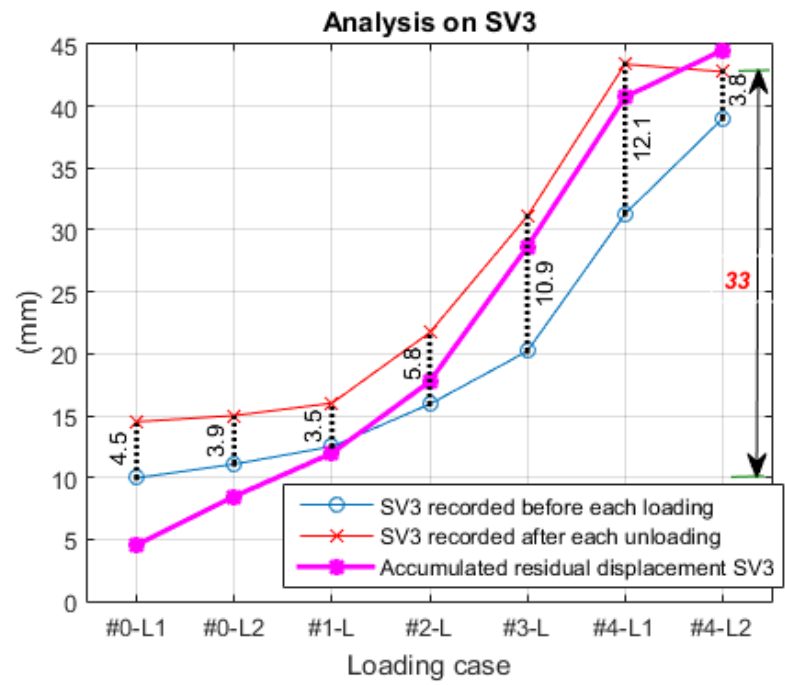

c) Only on SV3

Figure 12: Remaining displacements after each loading

Furthermore, Figure 12b allows localizing the damage by the strong increase of SV3, which passes over SV1 in scenarios \#3 and \#4. As SV1 is in the middle of the beam, it shows normally among all the transducers the highest deflection values. However when SV3, due to its close location to the cutting line, outpaces SV1, damage becomes evident at this position.

\subsection{Deflection curve and its derivatives}

The aim here is to establish deflection lines of the beam, referring to the initial (=zero) position of unloaded (UL) configuration. Since the first two loadings in Figure 9 were used just for stabilizing the system, these data are not considered. As static measurements started already before and as on January 22 some transducers were rearranged, we considered this moment subsequently as a new starting point. Hence, the absolute offset at this moment for every transducer was subtracted, so that 
we defined this position as new zero line for the un-deformed and un-damaged beam i.e. there from, vertical displacement in every point starts from zero.

Therefore, Figure 13 presents the deflection lines of the beam for both unloading (solid lines) and loading states (thick dashed lines) by connecting simply the measured values of SV1 to SV6. Two zero points are assigned to the two outer bearings, though there was no sensor. The data show 8 unloadings and 7 loadings from scenario \#0 to \#4. Prior to the appearance of vertical cracks, the deflection curves are quite smooth in the overall view. With cracking in \#3-L, maximum deflection moves from the middle (SV1) to nearly the cutting line between SV2 and SV3, proving that the monitoring of the deflection curves from the initial state to all the damage states allows localizing damage.

For comparison, the deflection lines are additionally smoothed by cubic spline interpolation. This interpolation assures the continuity of the first and second derivatives of the curves at the measurement points. Cubic spline interpolation implies boundary condition of zero curvature (second derivative) at the two extremities (bearings left and right). The interpolation results are presented in Figure 14 for the unloaded (UL) states and loaded (L) states.

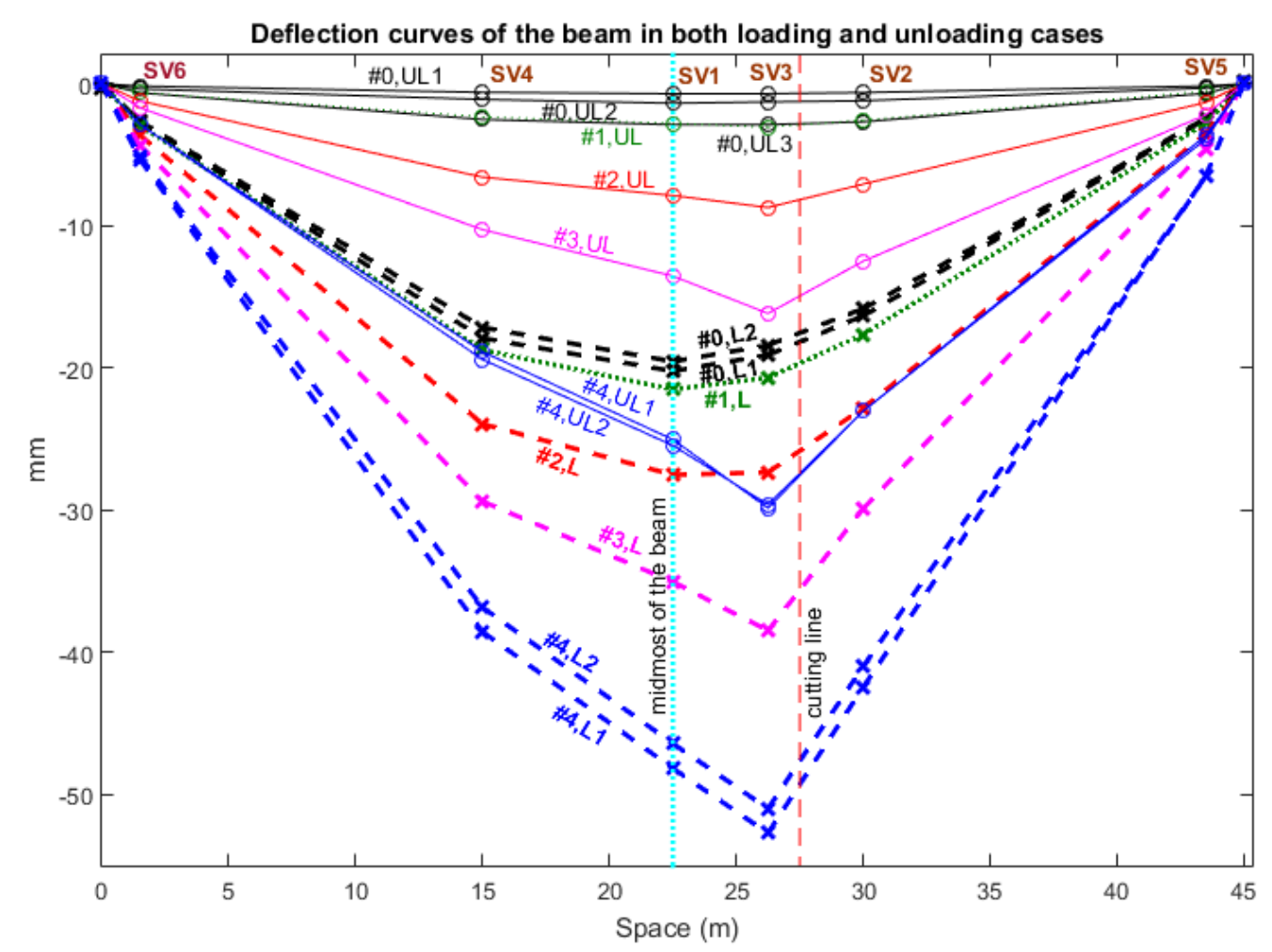

Figure 13 : Deflection of the beam in unloaded and loaded states, interpolated with straight lines 


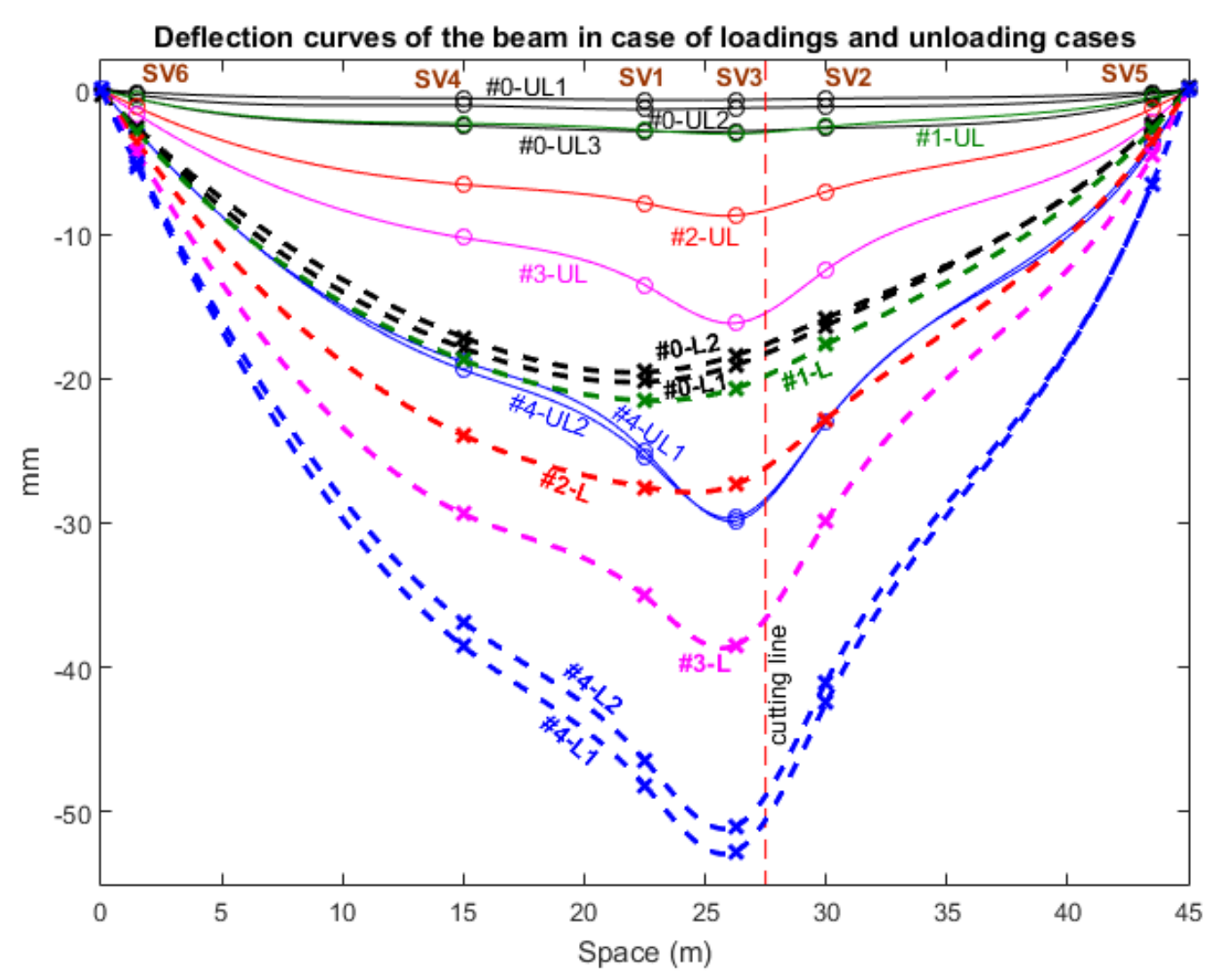

Figure 14 : Deflection of the beam in loaded and unloaded states by cubic spline interpolation

While damage can be visually and easily localized in Figure 13 by the absolute maximum of deflection and the monotonous sagging (see also Figure 12c), it is interesting to highlight the change in the shape of the curves near the cutting line in Figure 13. Naturally, the first derivative $w^{\prime}$ and the second derivative $\mathrm{w}^{\prime \prime}$ of the deflection curves $\mathrm{w}$ (namely slope and curvature) should be helpful for localization. If a deflection line $\mathrm{w}$ includes several discrete points with abscissa $x_{i-1}, x_{i}, x_{i+1} \ldots$, the slope and curvatures may be approximated as:

$$
\begin{aligned}
& \mathrm{w}_{\mathrm{i}}^{\prime}=\frac{\mathrm{w}_{\mathrm{i}}-\mathrm{w}_{\mathrm{i}-1}}{\mathrm{x}_{\mathrm{i}}-\mathrm{x}_{\mathrm{i}-1}} \text { at abscise } \frac{\mathrm{x}_{\mathrm{i}}+\mathrm{x}_{\mathrm{i}-1}}{2} \\
& w^{\prime \prime}{ }_{i}=\frac{w_{i+1}^{\prime}-w_{i}^{\prime}}{\frac{x_{i}+x_{i+1}}{2}-\frac{x_{i-1}+x_{i}}{2}}=\frac{w_{i+1}^{\prime}-w_{i}^{\prime}}{\frac{x_{i+1}-x_{i-1}}{2}} \text { at abscise } \frac{x_{i-1}+2 x_{i}+x_{i+1}}{4}
\end{aligned}
$$

The first numeric derivative (slope) is shown in Figure 15 for the unloaded states according to both the straight line and the cubic spline interpolation. The difference between the two interpolations and the numerical approximation of the derivatives are outlined in Table 5.

Table 5: Distinction between the two types of deflection lines

\begin{tabular}{lll}
\hline & From the straight line interpolation & From the cubic spline interpolation \\
\hline Deflection line & $\begin{array}{l}\text { Links } 8 \text { points: SV1 to SV6 + 2 boundary zero } \\
\text { points }\end{array}$ & $\begin{array}{l}\text { Cubic spline interpolated from } 8 \text { points - } \\
\text { cited in the left column }\end{array}$
\end{tabular}


$1^{\text {st }}$ derivative / Line includes 7 nodes

Slope

The first node is chosen between the first (fixed) bearing and SV6, the last node is between the second (sliding) bearing and SV5.

$2^{\text {nd }}$ derivative / Line includes 6 points Curvature
Derivative of the above cubic spline polynomial of degree 2

Derivative of the slope - polynomial of degree 1 (linear)

Based on straight line and cubic interpolation of the deflection lines, damage can be identified by strong variation of the slopes around the cutting line, as can be seen in Figures 15 and 16 for unloaded and loaded states respectively.

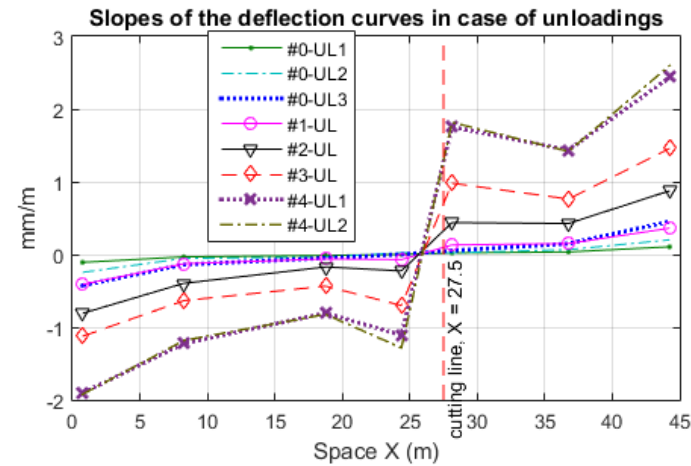

a) From straight line deflection

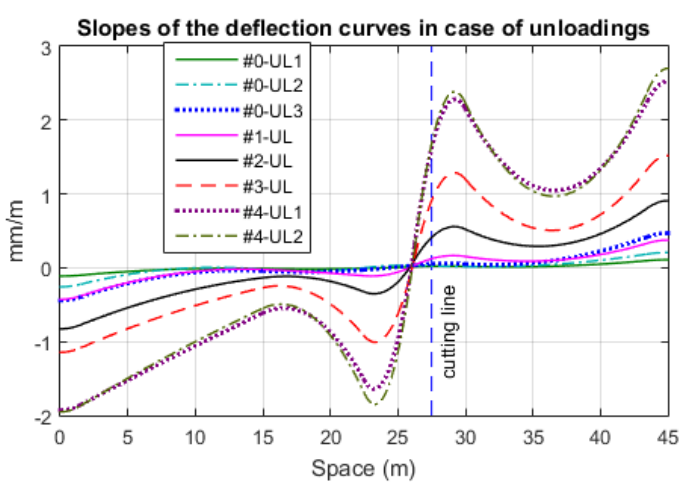

b) From cubic spline deflection line

Figure 15: Slopes for unloaded states

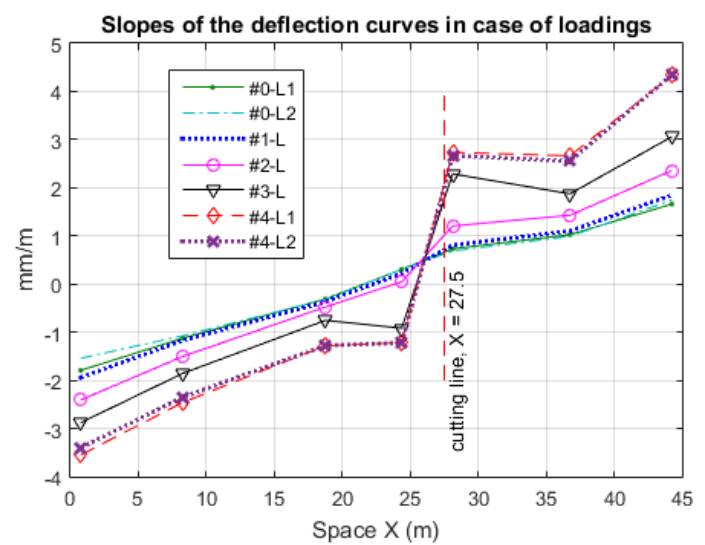

a) From straight line deflection

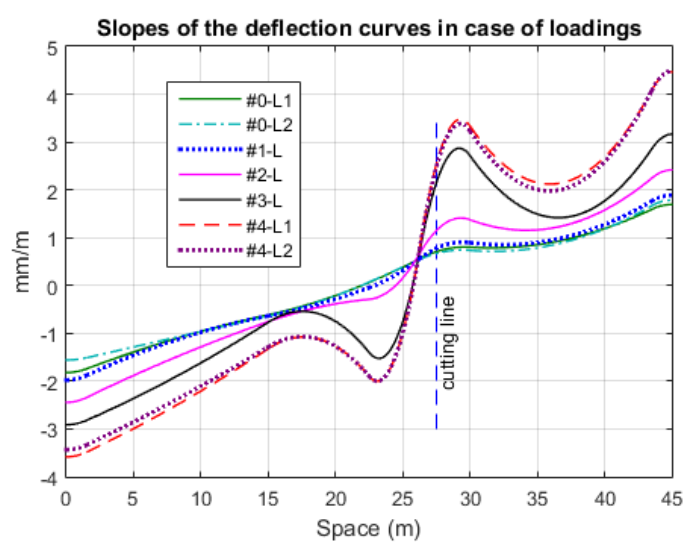

b) From cubic spline deflection line

Figure 16 : Slopes for loaded states

This strong variation leads to high values of curvatures near the cutting line, as shown in Figures 17 and 18. Damages can be accurately localized as the curvatures near the cutting line show local extremes in unloaded and loaded states. The curvatures are computed according to Table 5 and indicated at the respective axial distance $x$ (abscissa). The curvatures reveal clearly extremes at $x=26.3 \mathrm{~m}$, the sensor position near the cutting line. It shows that the damage localization is possible, efficient and accurate from damage state \#2 onwards for loaded and even for unloaded states with simple numerical derivations. It is reasonably robust with regard to the type of interpolation, i.e. linear or cubic spline. 


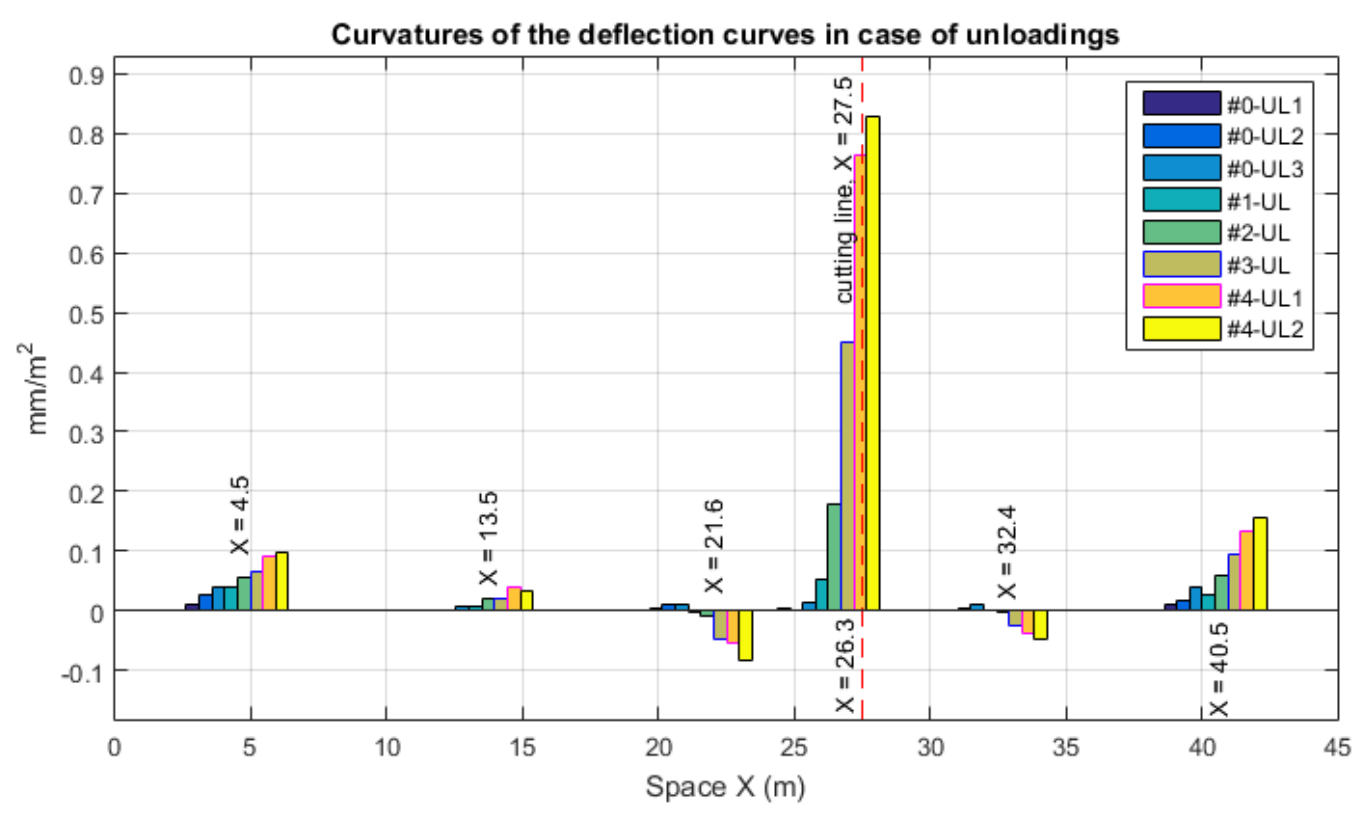

a) From straight line deflections

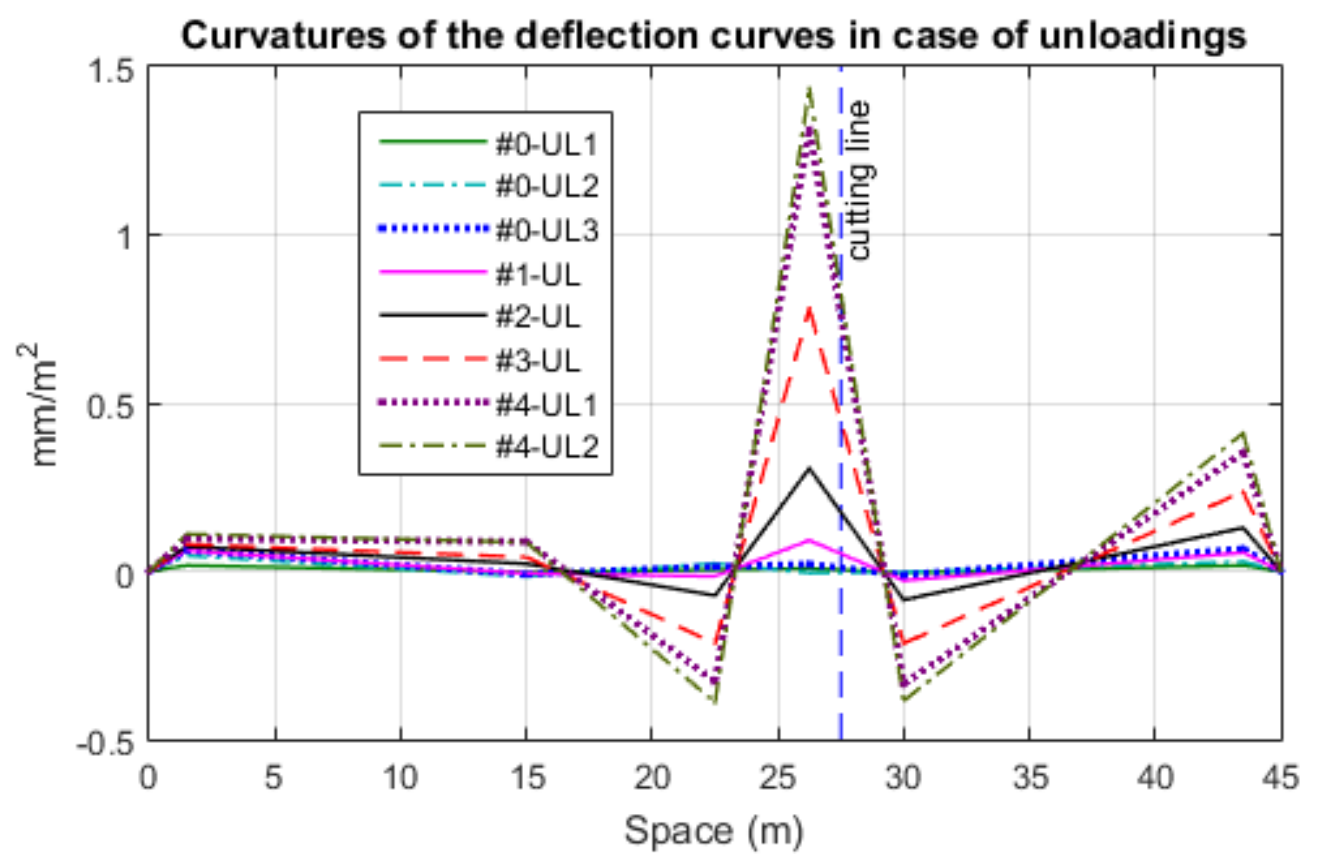

b) From the cubic spline deflection lines

Figure 17 : Curvatures for unloaded states

However, numerical approximation of the derivatives leads to errors, perceptible at the extremities of the curvatures at $x=0$ and $x=l$. The analytical solution of a simple beam shows zero curvature at both bearings, which is not exactly the case in Figures 17 and 18. This error is accumulated through two times of numerical derivation plus the assumption on zero displacement at the two extremities of the deflections lines. This was only an approximation, because in reality, the bearing has a finite length and stiffness and so is on top more than a point, as assumed in Figures 13, 3 and 4. 
Nevertheless, the localization is satisfactory and the level of damage is well indicated, for both loaded and unloaded states. The results show that the detections based on the raw deflection lines and the interpolation are quite similar.

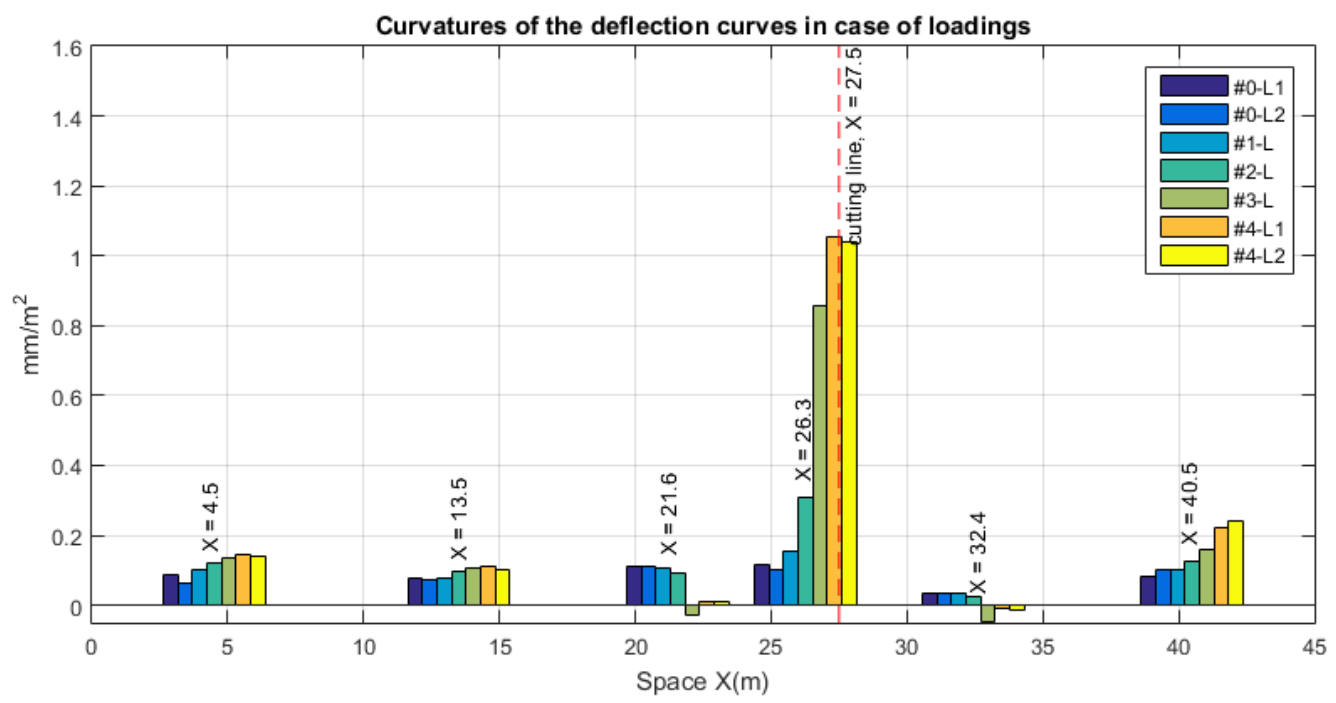

a) From the raw deflection lines

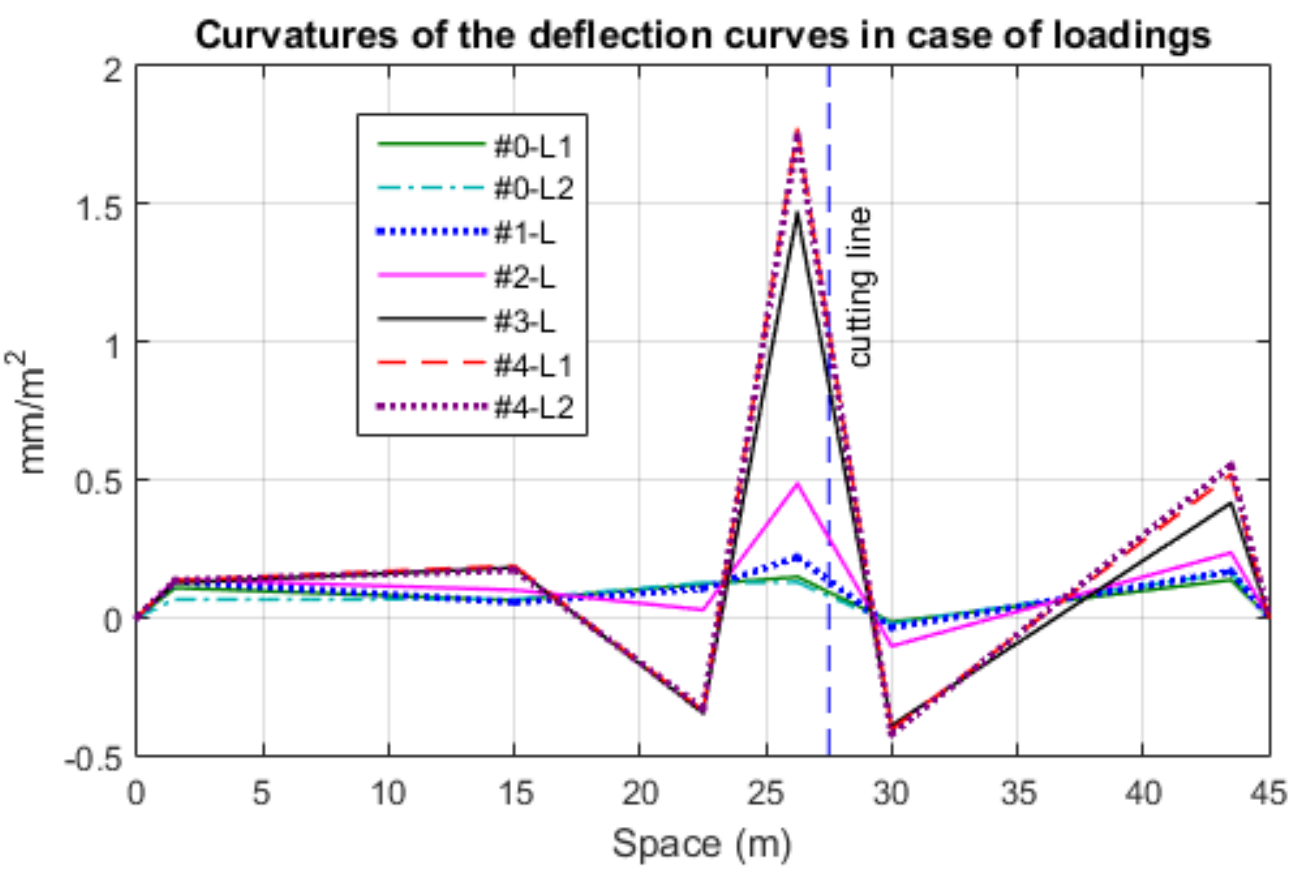

b) From the cubic spline deflection lines

Figure 18 : Curvatures for loaded states

\subsection{Variation of displacement due to temperature}

The temperature was measured in the beam by 7 sensors as shown in Figure 5 with the view from the East, i.e. the sunny side. As shown in Figure 19, the sensors T1, T5 and T7 show the highest variation (at the top and sunny side). T4 characterizes temperature of the bottom flange. To analyze the relationship between displacement and structural temperature, T4 (bottom flange) is correlated with 
vertical displacement SV1 (in the middle of the beam) and horizontal movement SH7 (close to the sliding bearing).

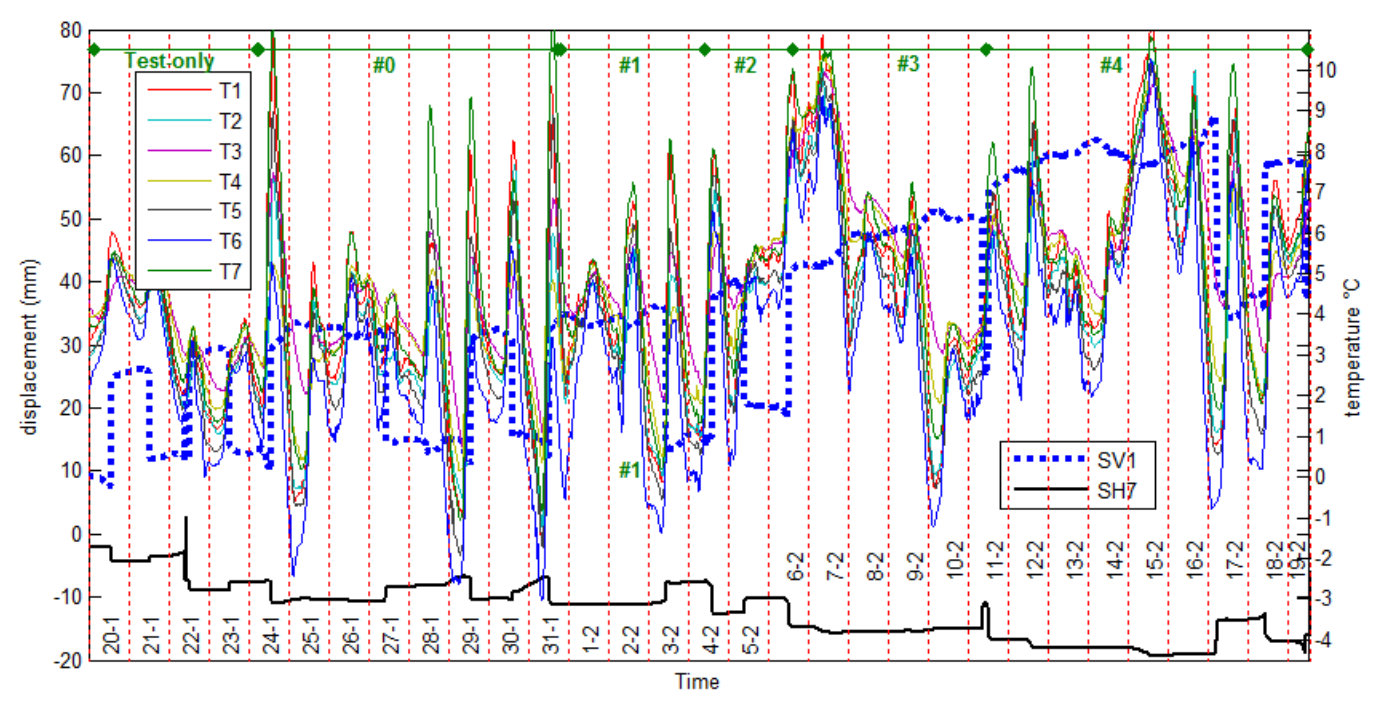

Figure 19: Temperature variations of the 7 sensors (right ordinate), shown together with two displacement signal SV1, SH7 (left ordinate)

Figure 19 shows temperature variations between $-3^{\circ} \mathrm{C}$ and $+10^{\circ} \mathrm{C}$, horizontal movements $(\mathrm{SH} 7$ in solid black) up to $20 \mathrm{~mm}$ and vertical deflections in SV1 (in the middle of the beam, dot blue) from 10 to $65 \mathrm{~mm}$. SV1 varies largely from unloading to loading and clearly reveals the discussed creep due to plastification. However, additionally there is an up-down movement linked to day-night temperature changes, though the measurements were done in winter with mostly overcast sky and moderate temperature variations. With sunshiny sky, the variations would have been by far more pronounced. The question is how to simplify the reading of static measurements or how to exploit useful data for condition monitoring or damage diagnosis. It would be very helpful, if temperature was constant and this up-down movement was eliminated.

In Figure 20, the midpoint deflection SV1 is plotted for all loadings only $(\mathrm{L})$ versus the bottom flange temperature $\mathrm{T} 4$, while Figure 21 shows the horizontal movement $\mathrm{SH} 7$ close to the sliding bearing over T4. Figure 22 and Figure 20 show basically the same data, but split in one graph for each loading. Magenta lines present all data, while dark blues select the same periods in both graphs (for overall plot and for each loading) with little or no horizontal movement, i.e. a more or less constant values in Figure 21 and Figure 23 respectively. For these "retained" data without horizontal movement, a linear regression line was calculated and added in green colour. (It should be noted that adding the green to the dark blue colour gives sometimes the impression of light blue colour). The horizontal movement is caused by temperature changes (expansion and contraction), but also by mechanical stresses generating axial strain (elastic or plastic incl. cracking). As well if there is no horizontal motion, we can detect an up and down movement in SV1. This might be caused by temperature difference between the top and bottom flange and due to blocked axial movement of our non-perfect sliding bearing. During the horizontal moving phases, a stick-slip effect of the sliding bearing is noticed which was caused by frictional forces. During a "stick-phase", the axial elongation/contraction generates vertical deflection, 
because the beam is clamped at both sides. Therefore, straight regression lines can be established in Figures 20-23, i.e. a linear variation of deflection with concrete temperature.

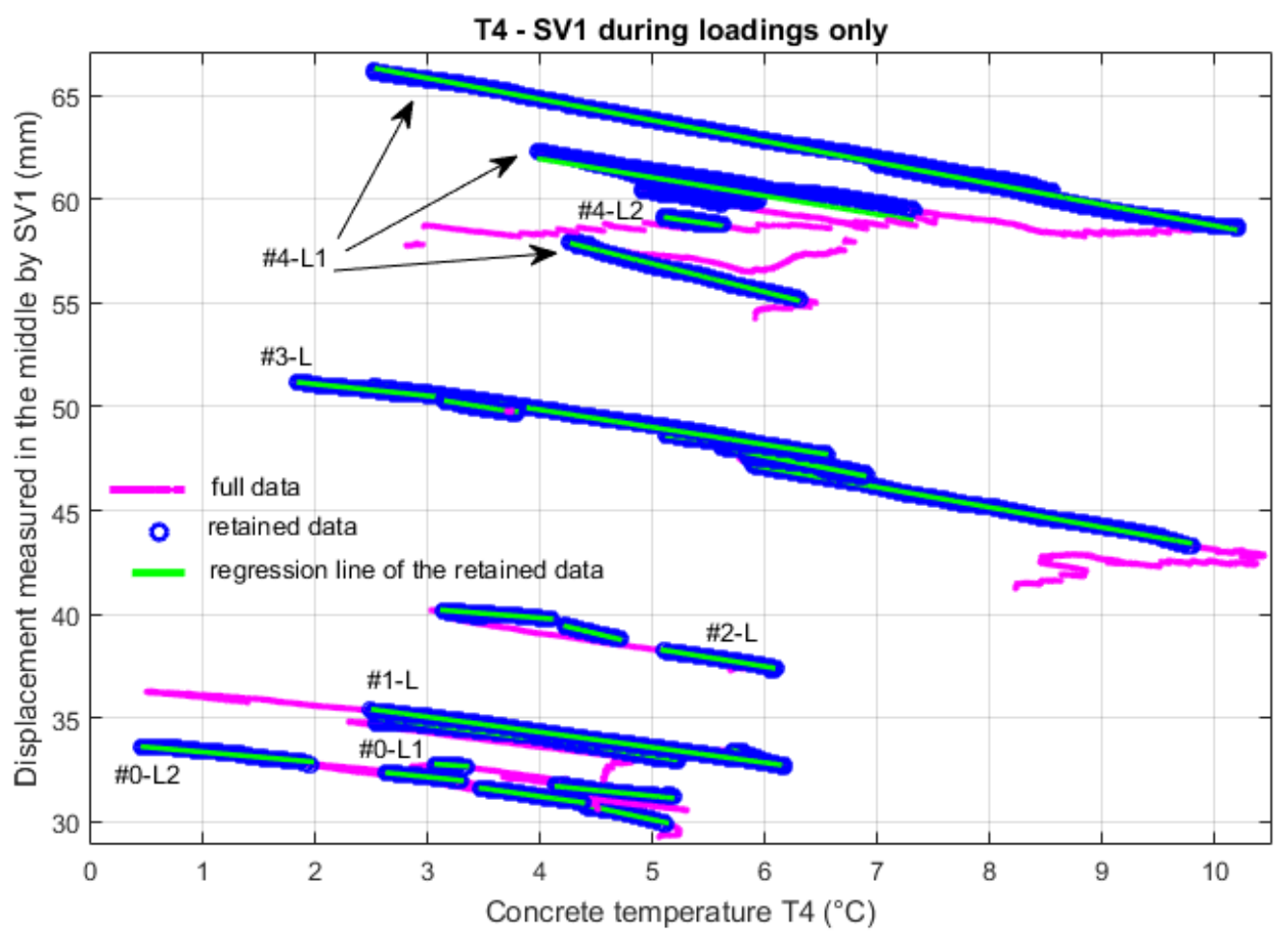

Figure 20: Relation between the temperature T4 and the vertical displacement SV1 in the middle

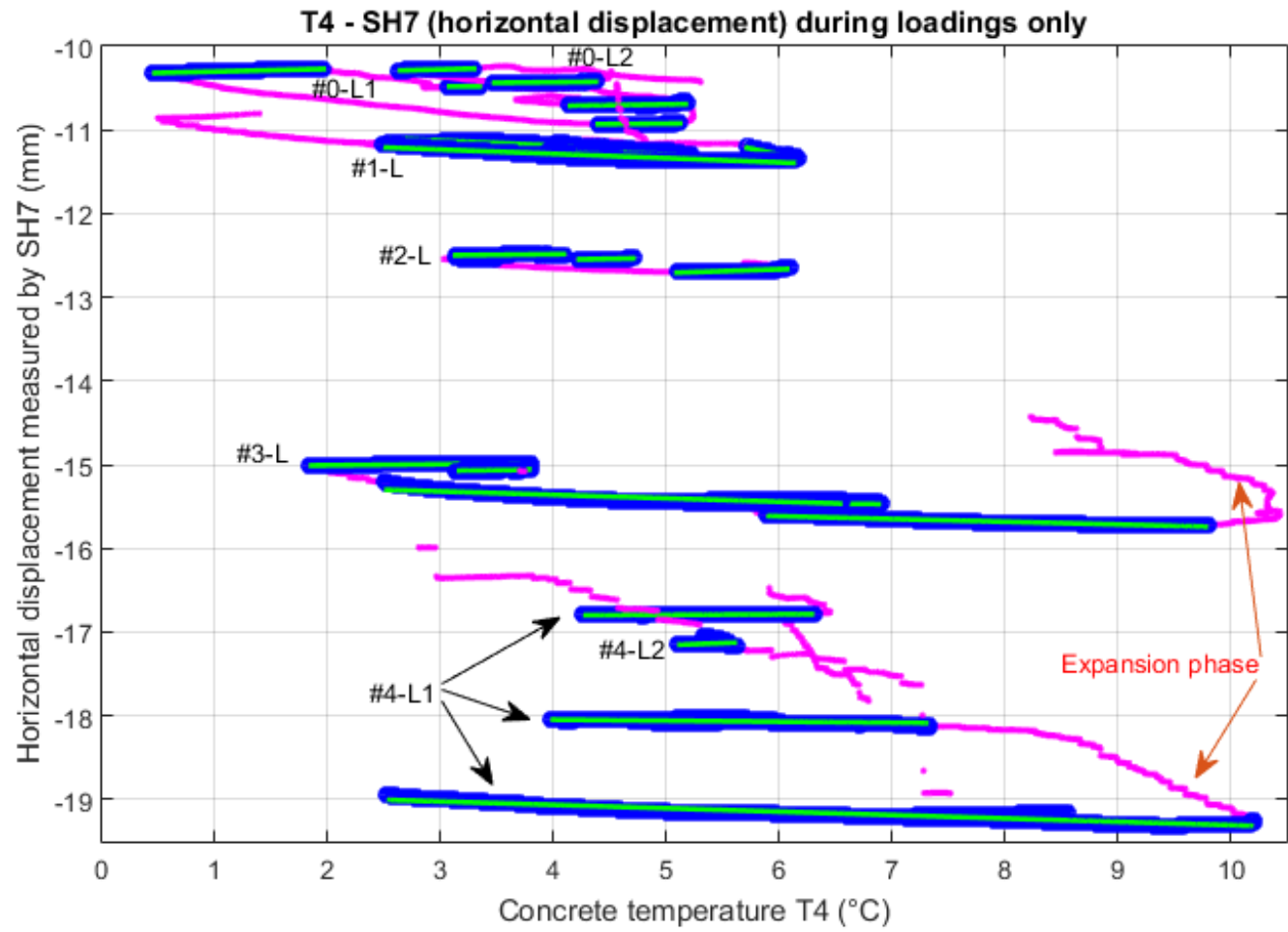

Figure 21: Relation between the temperature T4 and the horizontal displacement SH7 
As already mentioned, temperatures differences between top-side and bottom-side of the beam would lead also to vertical deflection even with an ideal and perfect sliding bearing which allows horizontal movements. In this case, the vertical deflection SV1 should be inversely proportional to the temperature difference $\Delta \mathrm{T}$ between top (T6, ref. to Figure 5 ) and bottom (T4) of the beam, i.e. $\Delta \mathrm{T}=\mathrm{T} 6$ T4. The corresponding plot SV1 versus $\Delta T$ is presented in Figure 24 for the same periods and the same notation of colours and type as preceding figures.
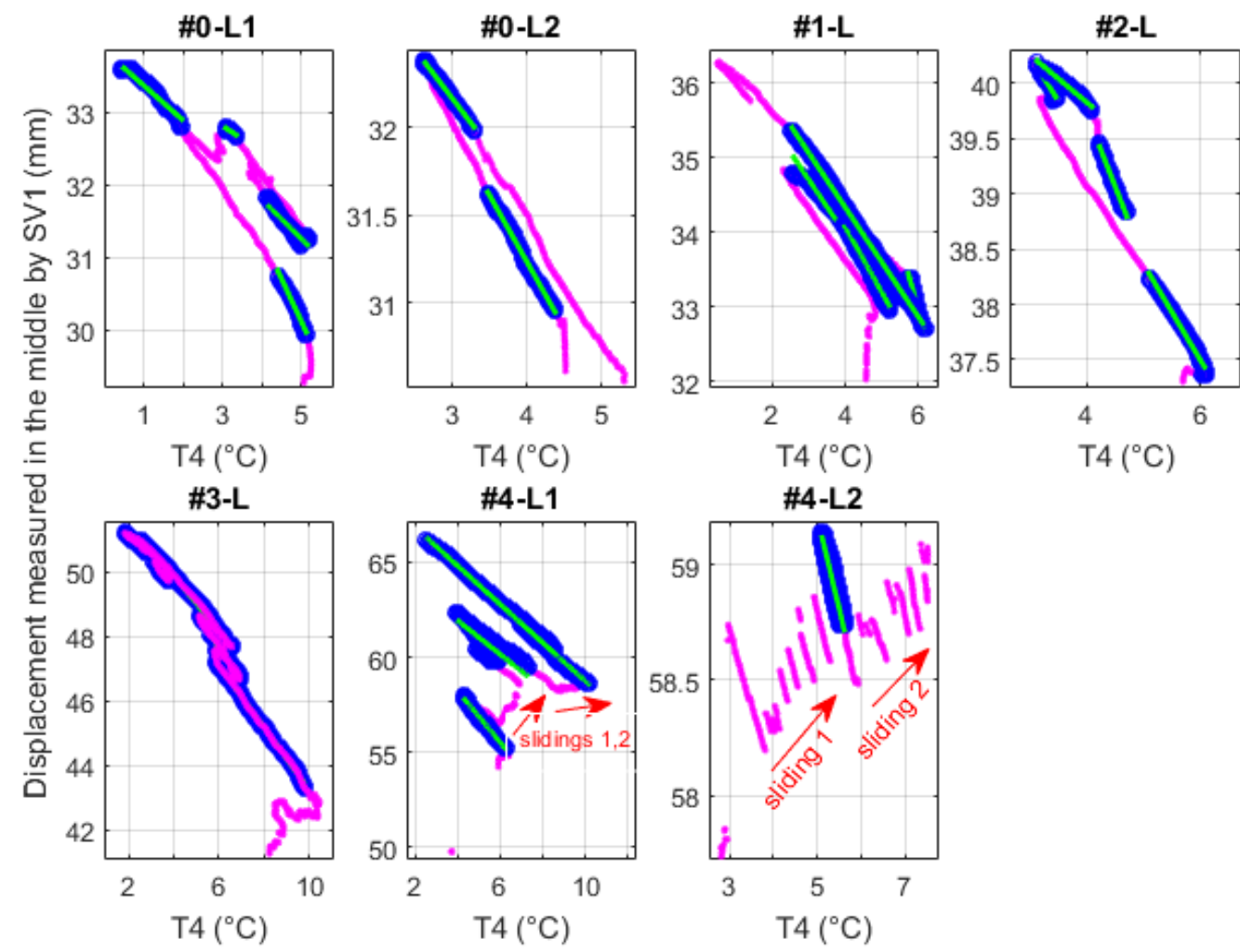

Figure 22: Zoom of Figure 20 for each loading 


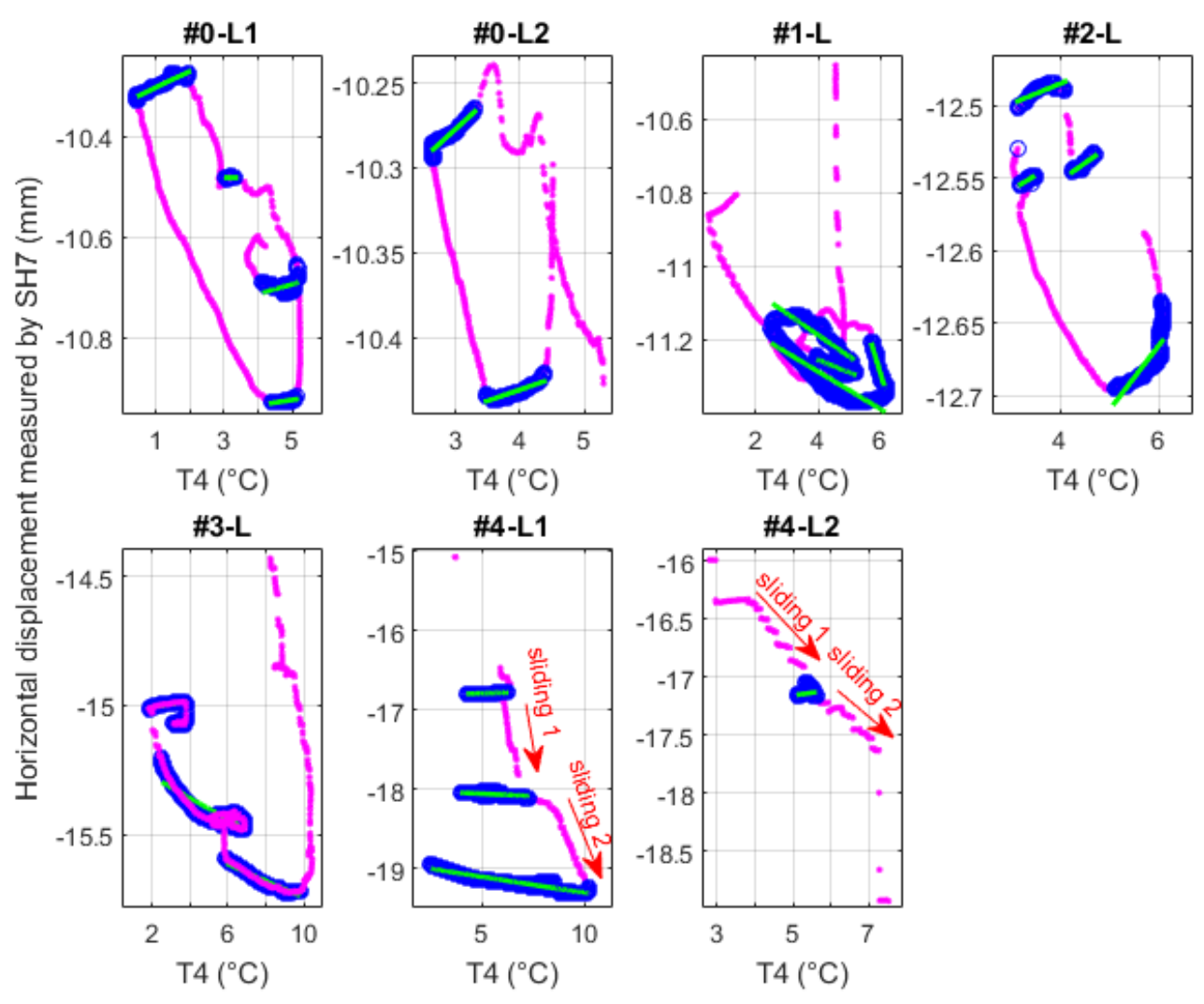

Figure 23: Zoom of Figure 21 for each loading
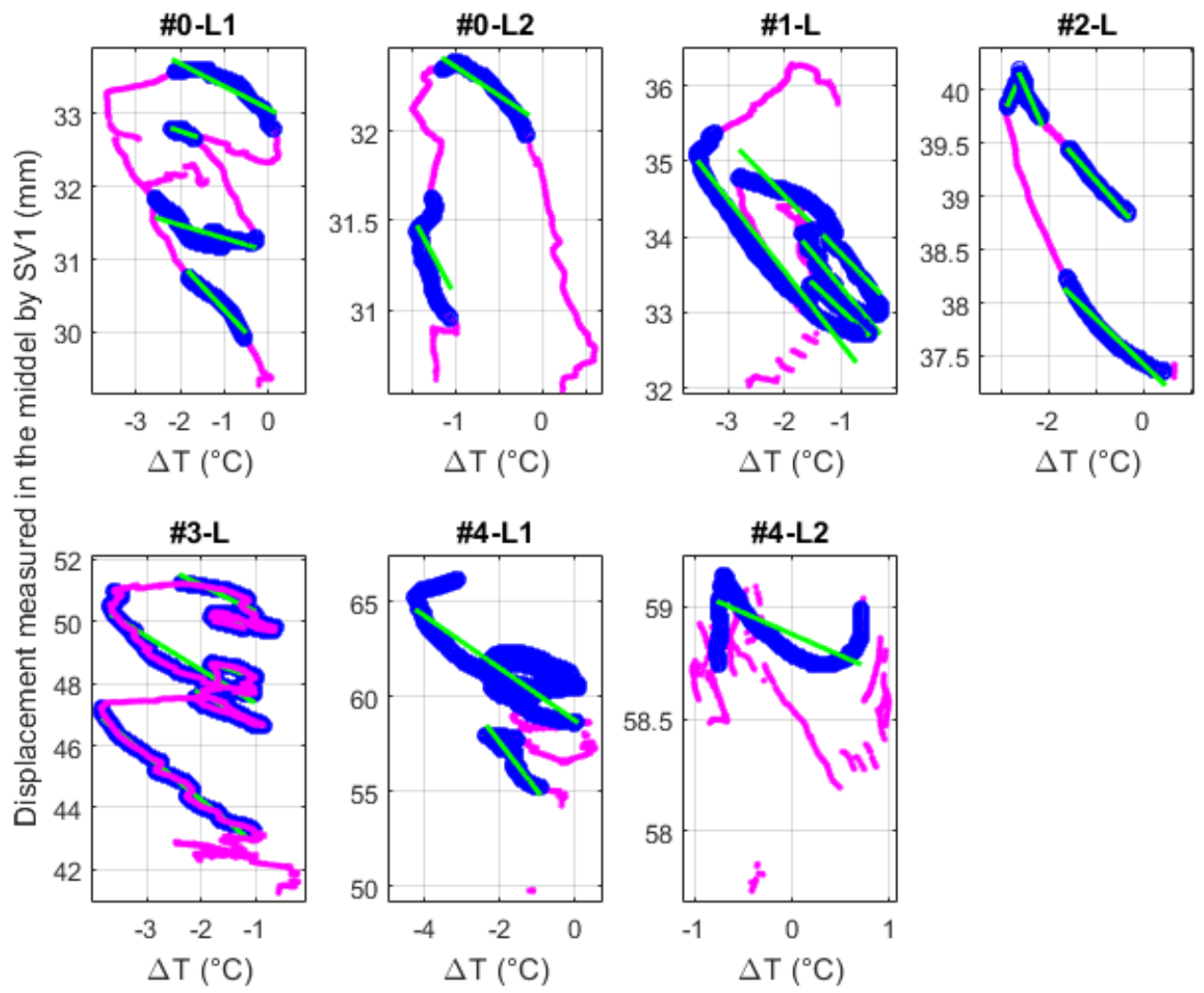

Figure 24: Relation between $\Delta T=T 6-T 4$ (top-bottom temperature) and the vertical displacement SV1 in the middle 
Comparing Figure 22 (SV1 versus T4) and Figure 24 (SV1 versus $\Delta \mathrm{T}$ ) we can detect that the 'branches' with respect to $\Delta \mathrm{T}$ are more curved, i.e. the slopes of the regression lines vary more, thus indicating that this correlation does not fit so well. At least, a tendency is again observed: an increase of $\Delta \mathrm{T}$ leaded to a decrease of SV1, similar to the case of T4-SV1. For instance a given negative $\Delta \mathrm{T}_{1}=$ $\mathrm{T}_{\text {top } 1}-\mathrm{T}_{\text {bottom 1 }}$, i.e. the top is colder than the bottom, that is almost observed in this structures as shown in Figure 25, we find in Figure 26 a given deflection $f_{1}$ that is more sagged than the deflection due only to loading (blue dash-dot curve). Reducing now the absolute value of $\Delta T$ versus zero, it makes reduce also the deflection to $f_{2}$ as sketched in Figure 26.

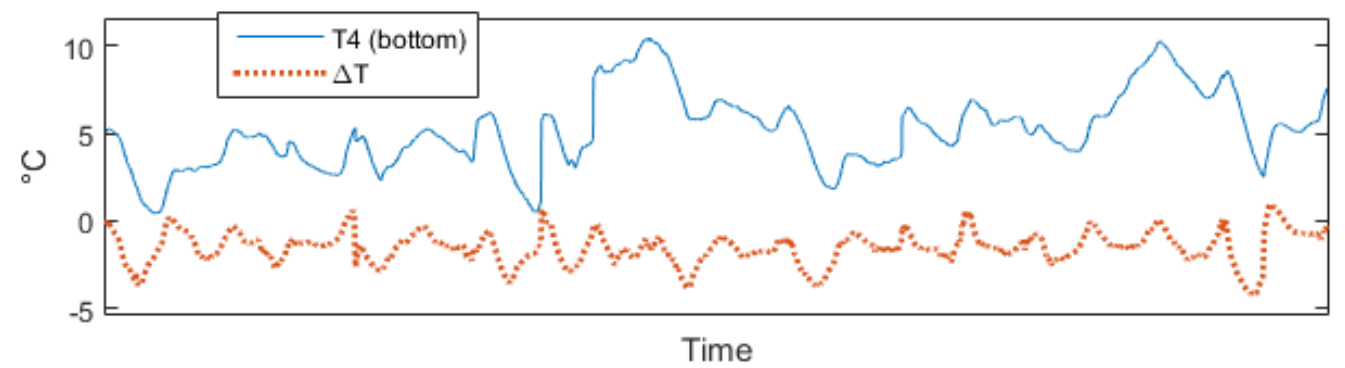

Figure 25 : Correlation between T4 and the gradient, shown for all loaded states

Figure 25 reveals that the fluctuations of $\mathrm{T} 4$ (bottom-flange temperature of the beam) and $\Delta \mathrm{T}$ are often consonant or in phase. An increase of $\mathrm{T} 4$ is often in line with an increase of $\Delta \mathrm{T}$, which leads finally to a reduction of the vertical displacement SV1. This explains the linear relation between SV1 and T4 in Figure 20.

$$
\begin{gathered}
T_{\text {top }}<T_{\text {bottom }} \\
\Delta T=T_{\text {top }}-T_{\text {bottom }}<0 \\
0>\Delta T_{2}>\Delta T_{1} \\
f_{2}<f_{1}
\end{gathered}
$$

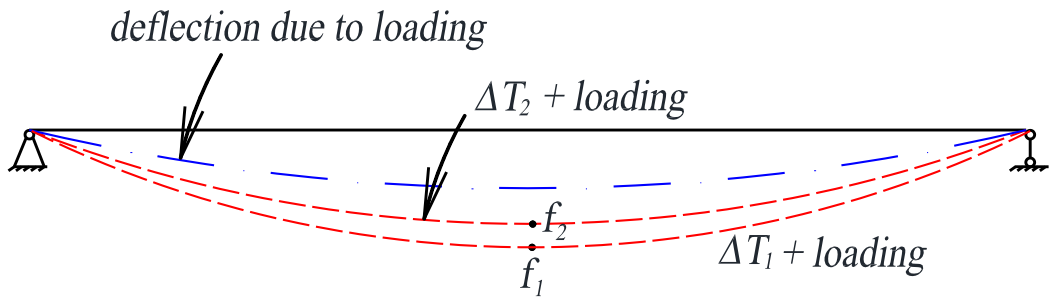

Figure 26: Bending deflection due to temperature gradient and its change by the variation of gradient

Furthermore, the 7 graphs in Figure 22 -Figure 23 show that each loading may contain several branches, but the inclinations of these branches are quite parallel (ref. to the overall view in Figure 20 and also to Figure 27). Loading \#4-L1 continues for $\approx 5$ days, as long as loading \#3-L (Figure 9). However in Figure 22, the data of loading \#4-L1 and also \#4-L2 are much more dispersed than of loading \#3-L, probably because no cracking and plastification was present in \#3-L. An increase of temperature during loadings \#4-L1 and \#4-L2 produces additionally horizontal movements and sliding as detailed in Figure 28. 


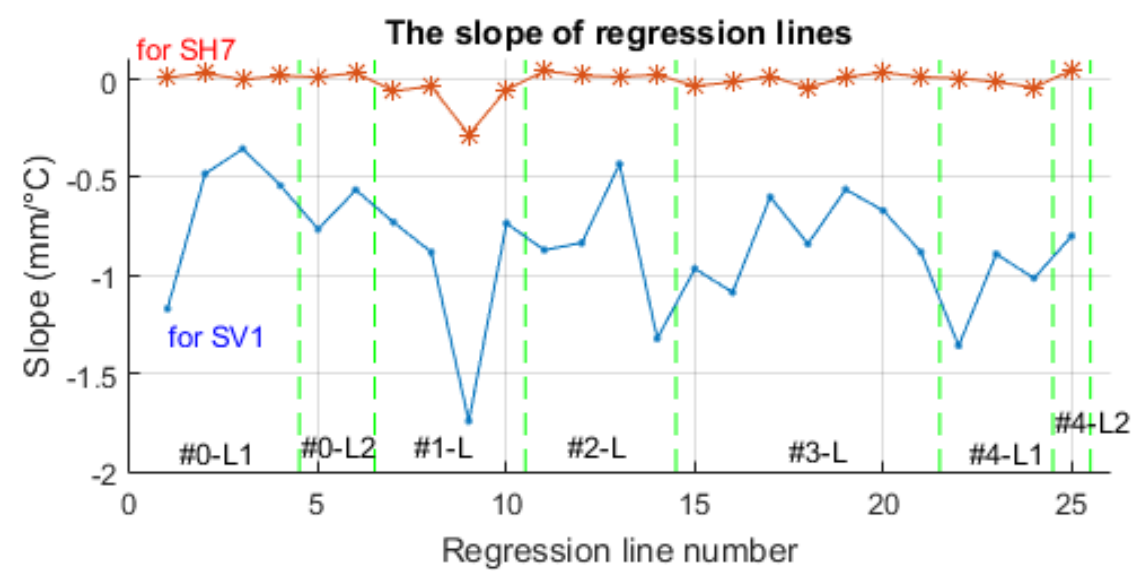

Figure 27: The slope of regression lines according to vertical SV1 and horizontal SH7

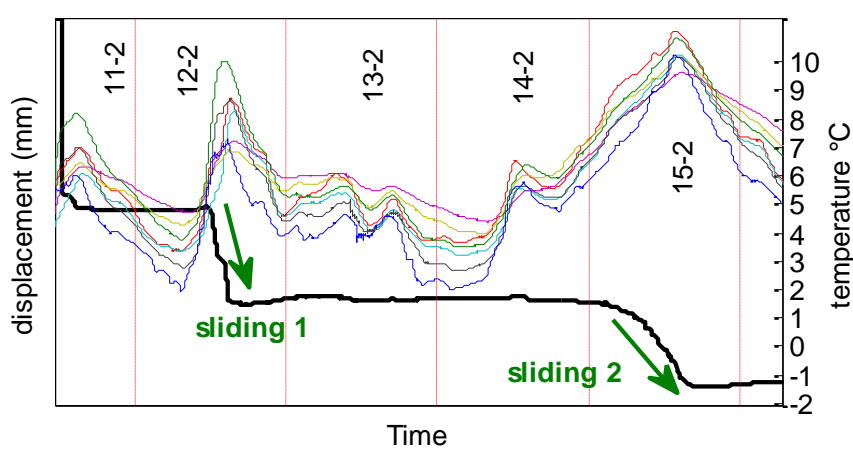

a) during loading \#4-L1

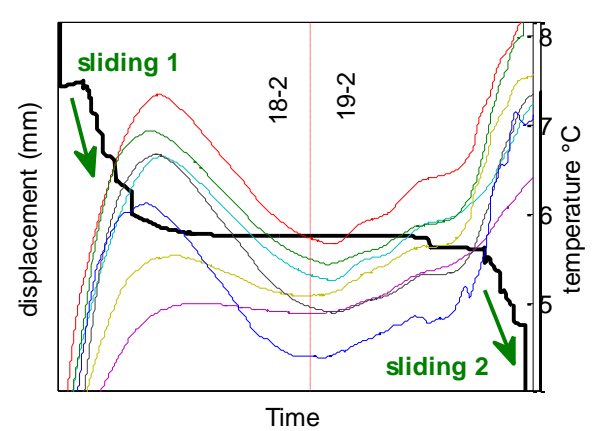

b) during loading \#4-L2

Figure 28: Stick-slips in the horizontal direction of the sliding bearing during damage \#4thick line: transducer $\mathrm{SH}$, thin lines: temperatures

\subsection{Temperature compensation for the displacement measurements}

As the regression lines are quite parallel (Figure 20, 22 and 27), a temperature compensation can be done by referring all measurements to a common temperature, for example $\mathrm{T} 4=5^{\circ} \mathrm{C}$. An example is given in Figure 29 to explain, how measured data X1, X2 are shifted to the chosen 'reference temperature of $5^{\circ} \mathrm{C}$ ' and represented by $\mathrm{Y} 1$ and $\mathrm{Y} 2$. This procedure is repeated for all 'retained' measured data, i.e. data without horizontal movement (ref. to Figures 20, 21 and the given description). These temperature-compensated values are shown in red in Figure 30. They are by far less fluctuant, corresponding by far better to the applied step-loading and hence permitting a better damage detection. 

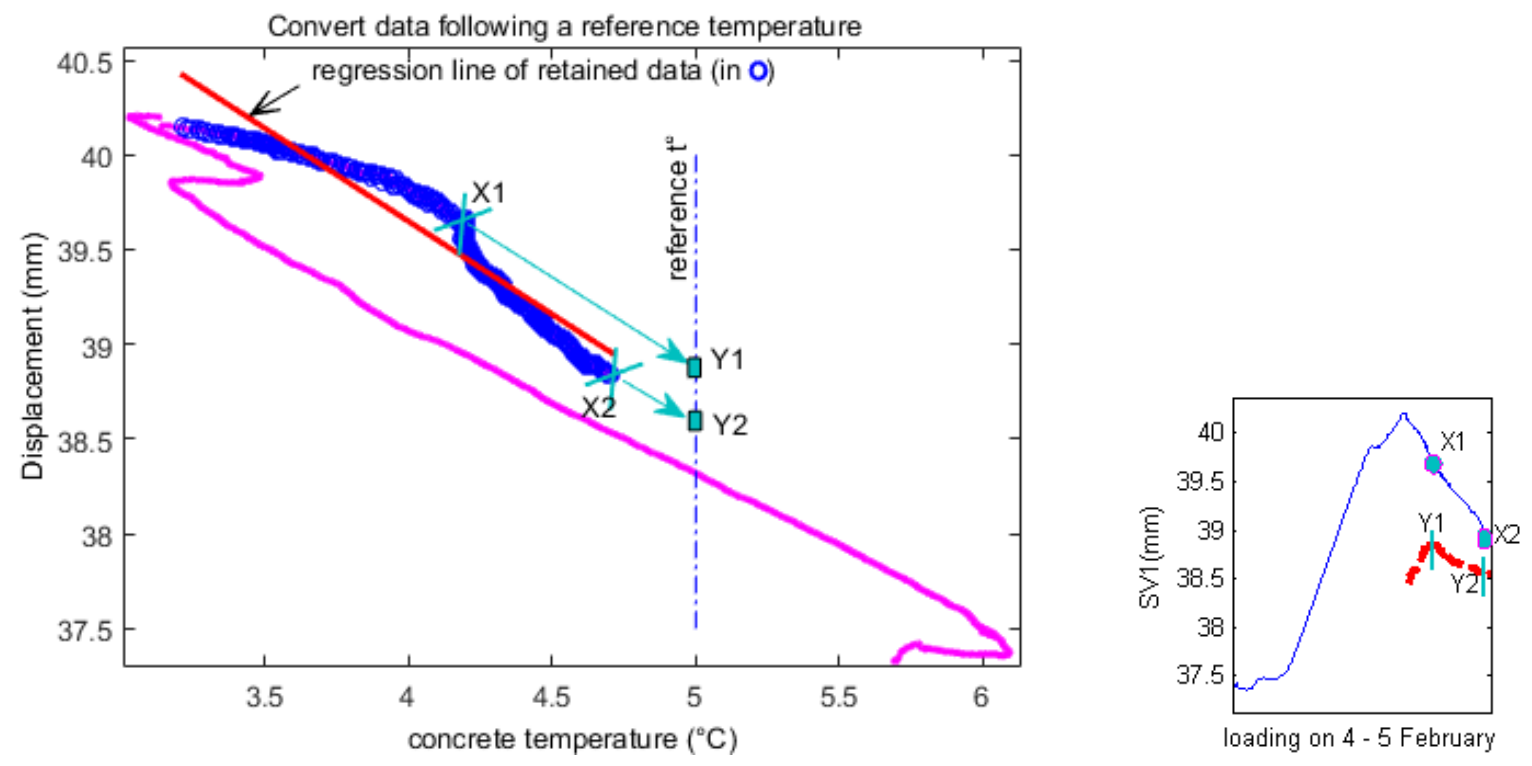

a) Data shown in the T4-SV1 plot

b) Data shown in the time-SV1 plot

Figure 29: Example of temperature compensation: 2 points $X 1$ and $X 2$ are projected with the mean slope of $1 \mathrm{~mm} /{ }^{\circ} \mathrm{C}$ to the reference temperature, resulting in new points $\mathrm{Y} 1$ and $\mathrm{Y} 2$

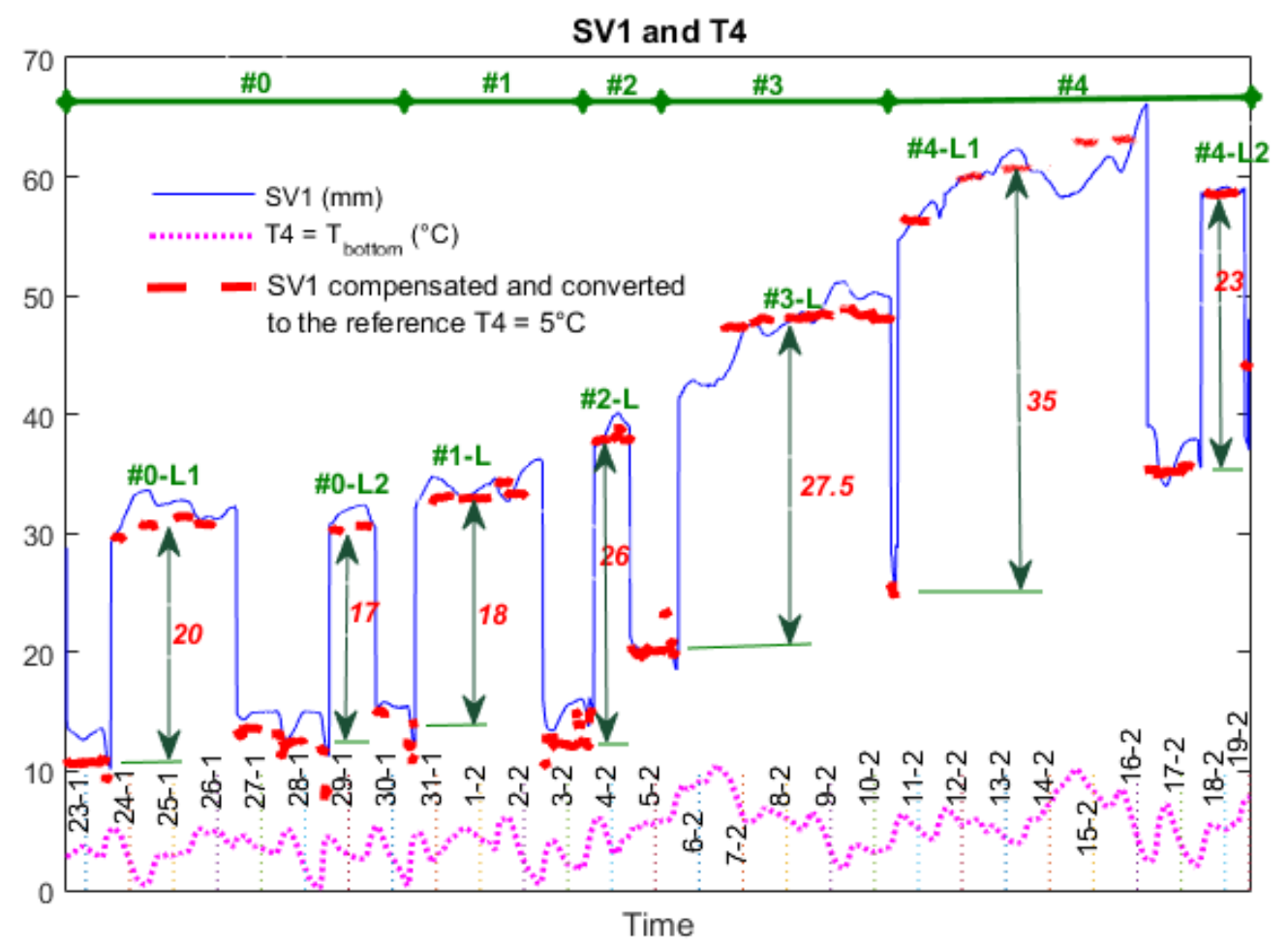

Figure 30: Vertical signal SV1 as measured (continuous blue) and compensated (thick red)

In Figure 30, the differences between loaded and unloaded data after the temperaturecompensation are introduced as red numbers and then reported in Figure 31. For damage states \#0 and \#4, we see a decrease between loading L1 and L2 due to the described effect in Figure 10, i.e. a residual elongation within the first loading due to cracking/plastification. From this perspective, all 
loadings have to be repeated at least twice in order to assure there is no plastification and hence compare correctly. Nevertheless, an increase of $6 \mathrm{~mm}$ (from 17 to $23 \mathrm{~mm}$ ) can be seen from \#0-L2 to \#4-L2, indicating progressive damage or reduced stiffness. It shows that the temperature-compensated step height can also be used as index for damage detection. But Figure 31 reveals furthermore, that the increase of step height by $6 \mathrm{~mm}$ is less pronounced than the sagging effect of $33 \mathrm{~mm}$ totally (ref. to Figure 12c).

It should be highlighted again that based on a comparison of Figure 22 with Figure 24, in the present case the absolute concrete temperature T4 was chosen as appropriate independent variable, while in other cases, this might also be $\Delta T=T_{\text {top }}-T_{\text {bottom }}$ as already discussed.

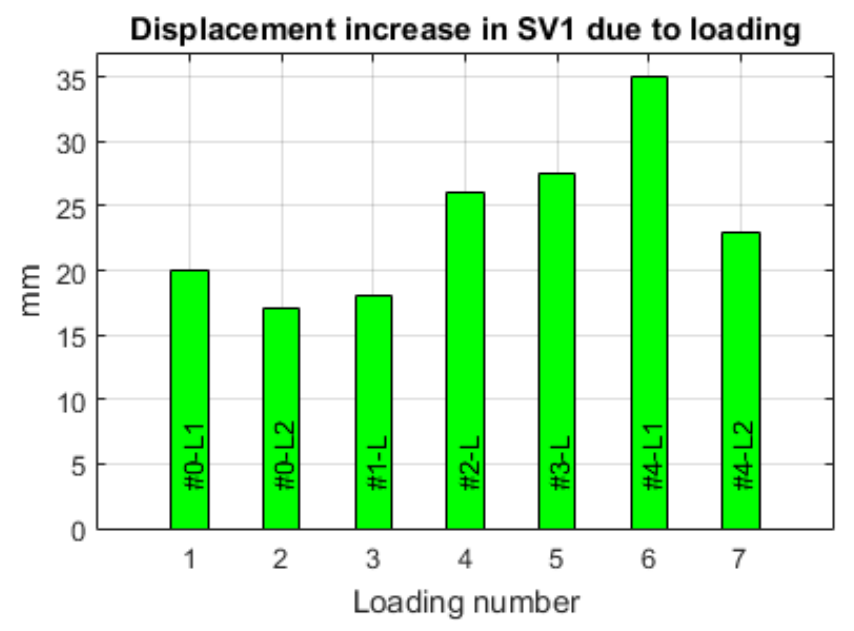

Figure 31: Step-height of compensated vertical deflection between loaded and unloaded state

\section{Summary and Discussion}

Concrete properties and prestress of tendons were verified, knowing that these are only random and local samples. The inspection of prestressed tendons showed also that due to the injection of mortar, the tendons were mostly joined to the concrete and hence anchored. Hence if a prestressed tendon fails, the damage is only local and will not affect directly the full length. But depending on the amount of passive reinforcement, the level of prestress and the actual charging and location, cracking of concrete may appear late and hence very close to collapse $[3,7]$. Hence, this may lead to brittle failure that may be very critical. This inconvenience can be overcome by adding passive reinforcement or by renouncing the grouting with mortar and leaving access to the tendons' ends. In this case, grease is used instead of mortar, which enables the control of the tendon's stress states at any moment and leaves the possibility of replacement if it is necessary.

This paper investigates repeated static load testing with always the same mass loading for structural health monitoring and damage detection. A prestressed concrete beam of a real bridge was jacked-up and artificially damaged in 4 steps by cutting tendons until wide vertical cracks occurred. The deflection line was permanently monitored during all the loading and unloading phases. The first and second derivatives of the deflection line, i.e. rotational angle and curvature, were numerically approximated, as these quantities have physical meaning in accordance with the Euler-Bernoulli beam theory. A zero line 
under own weight for the deflection was defined in the undamaged reference state and all subsequent load tests are referring to this zero line.

The deflection line changes obviously with damage: a plastic hinge is formed at the locus of the vertical cracks (position of damage) and the smooth deflection curve becomes somewhat angular. This change can be highlighted by derivation of the deflection line, but the sensor spacing must not be too small in order not to reduce the accuracy. If these restrictions are observed, the rotational angle and the curvature can be helpful damage indicators to detect the emerging local maximum.

As stated in the first paragraph of this section, the cutting of a tendon caused at first only local effects, i.e. a local loss of prestress, which does not always lead to cracking of concrete. Nonetheless, in accordance with the used FE models, the first vertical cracks appeared after the cutting of 6 among totally 19 tendons. The measurements showed that damage can effectively be localized from scenario \#3 (cutting of 6 tendons) onwards based on the deflection curves and from scenario \#2 onwards (cutting of 4 tendons) based on the changed curvatures. It is interesting to note that the maximum decrease of eigenfrequencies is only $4 \%$, which will be presented in a separate companion paper.

As cracking of concrete and plastification of reinforcement-steel are non-reversible and non-linear phenomena, the residual strain leads to a sagging of the bridge, which should be used as another damage indicator. This sagging under gravity is in principle monotonous, but may be hidden by temperature effects. The step-height in the deflection curve due to mass loading is traditionally also used as damage indicator, but less pronounced as often assumed. Nevertheless, attention should be paid that at least the structure is twice loaded then unloaded in order to separate plastic and elastic phenomena. Therefore, only the step-height from the second loading should be considered.

Finally, the absolute outdoor temperature and the temperature differences between top and bottom affect the measured deflection line. Unfortunately, this effect is unavoidable, but may be limited by choosing cloudy days for the measurements without high and direct solar irradiation, which additionally leads to local temperature differences [17]. A temperature compensation algorithm is proposed based on the slope of the deflection-temperature curve. This curve can be measured prior to damage detection in the healthy reference state and then used for subsequent temperature compensation. The proposed algorithm shows promising results in the discussed example based on the absolute temperature, but may also be used based on temperature differences, depending on the required forces for axial expansion/contraction, i.e. on the sliding bearing.

Thus, multiple indicators can be deduced from static loading tests, which are respecting the service limit-loading threshold.

\section{Conclusions}

Classically the deflection of a bridge during static load testing is measured with levelling (today electronic and digital) from topside with respect to a fixed reference point either apart or on the abutment of the bridge. Static quantities can be measured by other tools namely tilt or strain sensing as presented in [18]. In this work, static deformation was measured by displacement sensors, which was here an easy and reliable solution. Furthermore, long-gauge deformation sensors may be an interesting alternative 
as they cover the whole volume of a structure enabling a global monitoring with high resolutions [19]. Photogrammetric and GPS [20, 21] measurement technology have improved significantly in the last years and may hence also be used in future for quick and easy capturing of the deflection line under a test load and/or for detection of the sagging of the bridge under gravity referring to the supports, i.e. referring to an initially defined constant zero-line. However, practically, the repeatability and the absolute precision of all the different techniques is surely a topic of its own.

The repeated measurement of deflection lines with constant mass loading over years can also be used after temperature compensation for model-updating of finite element models, which in return can highlight stiffness reductions and hence damage.

\section{Acknowledgement}

The authors acknowledge the high value contribution of Administration des Ponts et Chaussées Luxembourg, specially Mr. Gilles Didier et Gilberto Fernandes.

\section{References}

[1] Reynders E., De Roeck G., "A local flexibility method for vibration-based damage localization and quantification", Journal of Sound and Vibration, Volume 329, Issue 12, 7 June 2010, pp. 23672383.

[2] M. Link, M. Weiland, "Extending a deterministic computational model updating technique to estimating the parameter variability caused by non-deterministic test data - a tool for Structural Health Monitoring, Proceedings of the International Conference on Noise and Vibration Engineering ISMA 2014, DOI: 10.13140/2.1.2414.7207.

[3] Mahowald J., Maas S., Waldmann D., Zürbes A., Scherbaum F., "Damage identification and localisation using changes in modal parameters for civil engineering structures", Proceedings of the International Conference on Noise and Vibration Engineering ISMA 2012, 17-19 September 2012, Leuven, Belgium, pp. 1103-1117.

[4] Nguyen V. H., Mahowald J., Maas S., Golinval J.-C., "Use Of Time- And Frequency-Domain Approaches For Damage Detection In Civil Engineering Structures", Shock and Vibration 2014(2), DOI: $10.1155 / 3148$.

[5] Nguyen V. H., Golinval J.-C., "Damage localization and quantification for Beam-like Structures using Sensitivities of Principal Component Analysis Results", Mechanical Systems and Signal Processing 24, 2010, pp. 1831-1843.

[6] Huth O., Feltrin G., Maeck J., Kilic N., and Motavalli M. "Damage Identification Using Modal Data: Experiences on a Prestressed Concrete Bridge", J. Struct. Eng. (2005) - ASCE, 131(12), pp. 18981910.

[7] Maas S., Zürbes A., Waldmann D., Waltering M., Bungard V., De Roeck G., "Damage assessment of concrete structures through dynamic testing methods. Part 2: Bridge tests", Engineering Structures, Volume 34, January 2012, Pages 483-494, doi:10.1016/j.engstruct.2011.09.018. 
[8] Khan M. A., Khan S. Z., Sohail W., Khan H., Sohaib M., Nisar S., "Mechanical fatigue in aluminium at elevated temperature and remaining life prediction based on natural frequency evolution", Fatigue \& Fracture of Engineering Materials \& Structures, Volume 38, Issue 8, pp. 897903, August 2015.

[9] Strauss A., "Numerical and monitoring based Markov Chain approaches for the fatigue life prediction of concrete structures", Engineering Structures, Volume 112, 1 April 2016, pp. 265-273, doi:10.1016/j.engstruct.2016.01.020.

[10] Inaudi D., "Long-Term Static Structural Health Monitoring", Structures Congress 2010 - ASCE: pp. 566-577, doi: 10.1061/41130(369)52.

[11] Issa M.A., Shahawy M.A., "Dynamic and static tests of prestressed concrete girder bridges in Florida", Proc IABMAS'04 Bridge Maintenance, Safety, Management and Cost, Kyoto. Taylor \& Francis, London, 2004.

[12] Ortiz O., Téllez J., Burgos F.J., Patrón A., Reyes E., Robles V., Cremona C., Ruiz-Sandoval M.E., "Load capacity assessment of "Antonio Dovali Jaime" bridge using static and dynamic tests", Tailor Made Concrete Structures - Walraven \& Stoelhorst (eds), Taylor \& Francis Group, London 2008, pp. $85-85$

[13] Caglayan B.O., Ozakgul K., Tezer O., "Assessment of a concrete arch bridge using static and dynamic load tests", Structural Engineering and Mechanics, Vol. 41, No. 1, 2012, pp. 83-94.

[14] Marefat M.S., Ghahremani-Gargary E, Nadery R. ,"Full-scale test of a 60-year-old mass concrete arch bridge", Koln, Germany, World Congress on Railway Research, 25-29 November; 2001.

[15] Marefat M.S., Ghahremani-Gargary E., Ataei S., "Load test of a plain concrete arch railway bridge of 20-m span", Construction and Building Materials 18 (2004) pp. 661-667.

[16] Waltering M., "Damage assessment of civil engineering structures and bridges using nonlinear dynamic characteristics", Dissertation PhD-FSTC-1-2009, University of Luxembourg.

[17] Maas S., Schommer S., Nguyen V. H., Waldmann D., Zuerbes A., "Some remarks on the influence of temperature-variations, non-linearities, repeatability and ageing on modal-analysis for structural health monitoring of real bridges", MATEC Web of Conferences, EVACES'15, 6th International Conference on Experimental Vibration Analysis for Civil Engineering Structures, October 2015.

[18] Stöhr S., Link M., Rohrmann R.G., Rücker W., "Damage Detection Based on Static Measurements on Bridge Structures", Conference \& Exposition on Structural Dynamics 2006 IMAC-XXIV, 30 January - 2 February 2006, St Louis, Missouri, USA.

[19] Rodrigues C., Inaudi D., Glisic B., "Long-gauge fibre optic sensors: performance comparison and applications", International Journal of Lifecycle Performance Engineering, Volume 1, Issue 3, DOI: 10.1504/IJLCPE.2013.058196.

[20] Avsar O., Akca D., Altan O., "Photogrammetric deformation monitoring of the second Bosphorus Bridge in Istanbul", The International Archives of the Photogrammetry, Remote Sensing and Spatial Information Sciences, Volume XL-5, 2014 ISPRS Technical Commission V Symposium, 23 - 25 June 2014, Riva del Garda, Italy. 
[21] Erol S., Erol B., Ayan T., "Analyzing the Deformations of a Bridge Using GPS and Levelling Data", Geodetic Deformation Monitoring: From Geophysical to Engineering Roles, Volume 131 of the series International Association of Geodesy Symposia, pp 244-253. 